\title{
DICIONÁRIO BOTÂNICO CLÁSSICO LATINO-PORTUGUÊS AVERBADO. IV- I-M
}

\author{
CARLOS TOLEDO RIZZINI \\ Pesquisador em Botânica \\ do Jardim Botânico do \\ Rio de Janeiro \\ e \\ CECILIA MARIA RIZZINI \\ Departamento de \\ Botânica Instituto de \\ Biologia, UFRJ
}

Continuando a apresentação do nosso dicionário para uso dos botânicos, seguem-se as letras compreendidas entre I e $\mathrm{M}$. As notas explicativas, como autores utilizados e abreviaturas, acham-se na "Advertência" da primeira publicação da série, nos Arquivos do Jardim Botânico (cf. Bibliografia).

IAM - Veja jam. Cf. denudatus.

IB. e IBID. - Abreviações de ibidem.

IBI, adv. - Aí, alí. Ubi stigma deest, ibi nulla foecundatio (Lp): onde falta o estigma, aí não há fecundação. Cf. dissertatio, exul, induo.

IBIDEM, adv. - Aí mesmo, lá mesmo. Serve ainda para evitar repetição de citação bibliográfica e de localidades (nesses casos, entende-se: no mesmo lugar antes citado). Ibid., pg. 27: à página 27 de uma publicação antes mencionada. Cf. existimo.

ICHNIOGRAPHUS, i, subs. m. 2 - Ilustrador. Ichniographi figuras Vegetabilium iconibus expresserunt (Lp): os ilustradores representaram as imagens das plantas por desenhos. Ichniographi rudes; usitatissimi: ilustradores toscos; utilíssimos.

ICHTHYOCOLLA, ae, subs. f. 1 - Cola de peixe. Cf. adglutinandus.

ICON, is, subs. f. 3 - Desenho. Iconibus illustrata: ilustrada (ou ilustrados, pl. n.) com desenhos. Pictores qui plantarum icones delinearunt $(\mathrm{M})$ : os pintores que traçaram os desenhos das plantas. Cf. adjectus, author, delineatus, graphice, ichniographus, index, mutuatus, omnis.

ICTURA, ae, subs. f. 1 - Picada. Ictura insectorum (FB): picada dos insetos.

ID, neutro sing. de is - Id est: isto é; comum abreviado: $i$. e.

Rodriguésia

Rio de Janeiro
Vol. XXXII - n.0 54

1980 
IDCIRCO, adv. - Por isso. Et genus idcirco incertum (FB): e o gênero, por esta razão, é incerto.

IDEA, ae, subs. f. 1 - Idéia. Ideam praebet floris multiplicati (Lp): dá uma idéia da flor multiplicada. Cf. essentialis, pauci.

IDEM, EADEM, IDEM, pron. e adj. - O mesmo, a mesma; aquilo mesmo (para não repetir algo antes mencionado). Gen. sing.: euisdem. Idem rex: o mesmo rei. Eodem modo sumpta, eundem effectum exhibet $(\mathrm{Pa})$ : empregada do mesmo modo, apresenta o mesmo efeito. In eodem loco: no mesmo lugar. Non dubito quin ad eandem speciem pertineant: não duvido que pertençam à mesma espécie. Existens praecipue eodem tempore, quo (Lp): existindo, sobretudo, ao mesmo tempo em que. Eaedem sunt (Lp): são a mesma coisa (são iguais). Gerit super eandem radicem flores (Lp): produz, sobre a mesma raiz, flores. In eadem planta (Lp): na mesma planta. Aloe et Agave idem genus constituebant (Lp): Aloe e Agave constituiam o mesmo gênero. Qui iisdem locis crescit (FB): o qual vive nos mesmos lugares. Cf. aculeus, collaticius, debeo, domicilium, eadem, eiusdem, fio, fumus, genus, hilum, ille, intuitus, involvo, milito, obtineo, pars, propemodum, repetitus, semen, specto, uterque, visus.

IDENTICUS, a, um, adj. - Idêntico. Cf. pro.

IDE0, adv. - Por isso. Ideo quia: por que. Chrysocantes dicitur ideo quia grana fert coloris aurei $(\mathrm{Pa})$ : chama-se Chrysocantes por que produz sementes de cor dourada. Legumen ignotum et ideo genus subincertum (FB): o legume é desconhecido e por isso o gênero é algo duvidoso.

IDEOQUE, adv. - E por isso. Est ideoque crassior (Lp): e, por isso, é mais espesso. Affinis ideoque iis adsociata (FB): afim e por isso ligada a elas. Species plane dubiae ideoque delendae (FB): espécies nitidamente dúbias e por isso devem ser eliminadas.

IDIOMA, ae, subs. f. 1 - Língua. Cf. belgicus, conscriptus.

IDONEUS, a, um, adj. - Idôneo, próprio, conveniente. Floribus ad analysin non idoneis (FB): pelas flores impróprias para a análise.

IGITUR, conj. - O mesmo que itaque, mas colocado em segundo lugar, por via de regra. Também adv. Pollinis granulis microreticulatis, pro nova specie igitur eam habeo: pelos grãos de pólen microrreticulados tenho-a, portanto, na conta de espécie nova. Sursum igitur crescit: para cima, portanto, cresce.

IGNARUS, a, um, adj. - Ignorante; inexperiente; desconhecido. Non desunt pharmacopolae rei herbariae penitus ignari $(M)$ : não faltam droguistas totalmente ignorantes de Botânica.

IGNORANTIA, ae, subs. f. 1 - Ignorância, desconhecimento. Cf. prodo.

IGNOTUS, a, um, adj. - Desconhecido, ignorado. Flores feminei hucusque ignoti (FB): as flores femininas até agora desconhecidas. Cf. adhuc, affinitas, ideo.

IGNORO, ignoremus - Ignorar, desconhecer. Cf. licet (conj.). 
IIS - Dat. e abl. pl. de is. Também: eis. Ut iis pecora excludentur (Lh): de modo que, por meio deles, sejam repelidos os animais (domésticos). Cf. similis.

ILIGNUS, a, um, adj. - Relativo ao carvalho. Cf. lignum.

ILLAPSUS, us, subs. m. 4 - Corrente, vertente (de água). Mediante pollinis antherarum illapsu (Lp): por meio de uma corrente de pólen das anteras.

ILLE, illa, illud, pron. e adj. - Aquele, aquela, aquilo; ele, ela; o, a. Gen. sing. illius, pl. illorum, illarum, illorum. Expletivo. Ille frutex sat frequens, hic perrarus: aquele arbusto é bastante freqüente, este muito raro. Radix est illi ima parte villosa (M): a raiz, na sua parte mais baixa, vilosa. Connectens illud cum germine (Lp): ligando aquele com o ovário. Illae ad idem genus pertinent $(\mathrm{Lp})$ : elas pertencem ao mesmo gênero. Cf. apprime, frustullum, marcesco, nescio, nomenclatio, quadro, qui, respondens, situs, stirps, surculus, vulgarior.

ILLEPIDUS, a, um, adj. - Sem graça, insípido. Cyperacea illepida (FB): Ciperácea feia, grosseira.

ILLIC, adv. - Alí, lá.

ILLINITUS, a, um, adj. - Esfregado, untado com. Herbae sucus illinitus cum aceto summe prodest $(\mathrm{Pa})$ : o suco da erva aplicado com vinagre é muitíssimo útil.

ILLINO, illinitur - Esfregar, untar com, aplicar sobre. Cf. resina.

ILLIUS - Gen. sing. de ille, illa, illud.

ILLORUM, illarum, illorum - Gen. pl. de ille, illa, illud.

ILLUMINATUS, a, um, adj. - Enfeitado, ornado, embelezado. Figurae coloribus illuminatae (Lh): figuras enriquecidas (ou ornadas) com cores.

ILLUSTRATUS, a, um, adj. - Pintado, ilustrado; esclarecido. Character fuse illustratus (FB): caracteres minuciosamente explicados. Cf. icon.

ILLUSTRIS, e, adj. - Brilhante, lustroso; distinto, ilustre. Species illustris pulchritudine (FB): espécie célebre pela beleza.

ILLUSTRO, illustrant, illustravit - Manifestar; esclarecer, tornar evidente; celebrizar. Cf. exemplum, non.

IMAGO, aginis, subs. f. 3 - Imagem; reflexo; desenho, figura. Plantarum et animalium imagines (M): os desenhos de plantas e animais. Cuius hic imaginem damus (M): do qual damos aqui a figura. Fungus penis imaginem referens (Lh): o cogumelo com aspecto de penis. Cf. appingo, catalogus, curo.

IMBER, imbris, subs. m. 3 - Chuva, chuvarada. Cf. juvo.

IMBERBIS, e, adj. - Destituído de barbas, espinhos, etc. Filamenta omnia imberbia

(FB): todos os filetes sem pêlos. 
IMBRICATUS, a, um, adj. - Imbricado, um cobrindo parte de outros numa série. Ut invicem se quoad partem tegant (Lp): de maneira que se cubram, parcialmente, umas às outras. Imbricata si conferta erecta simul sint (Lh): (as folhas) são imbricadas quando ao mesmo tempo, confertas e erectas - especialmente as opostas decussadas (Lavoisiera). Desse modo, uma cobrem parcialmente as outras - como telhas num telhado. Dizemos também imbricativa, menos vezes. Prefoliação imbricada: as jovens folhas dispõem-se como acima se referiu. Cf. serratus, squamosus, sursum, tectus.

IMBUTUS, a, um, adj. - Impregnado. Flores colore roseo rubrove imbuti (FB): flores impregnadas de cor rósea ou vermelha (flores róseas ou vermelhas, simplesmente).

IMMATURUS, a, um, adj. - Verde, não maduro; prematuro. Cf. germen.

IMMEDIATE, adv. - Imediatamente, logo; diretamente. Cf. adnecto, exeo, radicalis, sessilis.

IMMENSUS, a, um, adj. - Imenso, vasto. Cf. labor.

IMMERSUS, a, um, adj. - Imerso, mergulhado na água. Perithecia thallo sunt immersa: os peritécios são afundados no talo. Cf. fovea, gelatina, gregatim, perithecium.

IMMIGRATUS, a, um, adj. - Emigrado; introduzido. Species immigrata (FB): que passa do país de origem para outros; procedente doutro país.

IMMITTO, immittes - Enviar para dentro; deixar; etc. Cf. sub (prep.).

IMMIXTUS, a, um, adj. - Misturado. Cf. anaphysis.

IMMO (imo), adv. - Pelo contrário; até mesmo. Immo omnium florum genuina consideratio (Lp): e até mesmo a correta observação de todas as flores. Species P. splendenti proxima, fortasse immo mere eius variatio: espécie próxima de $\mathbf{P}$. splendens, mais ainda, talvez mera variedade dela. Rarius suffrutices imove herbae (FB): mais raramente subarbusto ou até mesmo ervas.

IMPALPABILIS, e, adj. - Impalpável. Continet materiam impalpabilem (Lp): contém uma substância impalpável (insignificante).

IMPAR, imparis, adj. - Impar, desigual. Cf. pinnatus.

IMPARIPINNATUS, ta, tum, adj. - Imparipenado ou imparipinado, folha composta penada que finaliza por um folíolo isolado. O mesmo que pinnatus cum impari (Cf. pinnatus).

IMPARTITUS, a, um, adj. - Não partido. Lamina impartita (FB).

IMPATIENS, impatientis, adj. - Que não suporta; impaciente. Plantae frigoris impatientes (Lp): plantas mal suportando o frio.

IMPENSE, adv. - Muito. Cf. redolens.

IMPERATOR, oris, subs. m. 3 - Comandante, imperioso. Cf. medicus. 
IMPERFECTUS, a, um, adj. - Imperfeito, não acabado de todo. Fungi imperfecti, Lichenes imperfecti: fungos, liquens não perfeitamente conhecidos (o aparelho esporígeno). Cf. apetalus, exemplar, parenchyma.

IMPERIUM, i, subs. n. 2 - Império, região geográfica. Genus imperii 4 (FB): gênero da região n. 04 (na enumeração do autor). Cf. metropolis.

IMPERSCRUTABILIS, e, adj. - Impenetrável. Substantiam sensibus nudis imperscrutabilem (Lp): uma substância impenetrável aos sentidos desarmados.

IMPIGERRIMUS, superl. de impiger, gra, grum, adj. - Intensíssimo, muito ativo. Cf. labor.

IMPLEO, implentur - Encher alguma coisa de outra; fartar; completar, totalizar. Monopetali rarius implentur $(\mathrm{Lp})$ : os monopétalos mais raramente se enchem (= tornam-se plenus - veja impletio).

IMPLETIO, onis, subs. f. 3 - 0 tornar-se plenus: aumento anormal do número de pétalas ou de nectários; plantas cultivadas. Impletio florum simplicium vel petalis vel nectariis peragitur (Lp): o "enchimento" das flores simples refere-se ou às pétalas ou aos nectários.

IMPLETUS, a, um, adj. - Cheio, farto, completo. Cellulae granulis chlorophylli virescentibus impletae (FB): as células cheias de grãos esverdeados de clorofila.

IMPLEXUS, a, um, adj. - Enovelado, embaralhado; entrelaçado. Thallus hyphis implexis: talo com hifas entrelaçadas.

IMPLICATUS, a, um, adj. - Enlaçado, emaranhado; unido. Rhizoma massam implicatam formans (FB): rizoma que forma massa entrelaçada.

IMPONO, imponito, impone, imponat, imposuit - Pôr em ou sobre; pôr à frente de; impor, exigir; aplicar, dar. Cf. aluta, butyrum, denominatio, donec, tritus, unde.

IMPORTO, importari - Importar (mercadorias); causar, produzir. Cf. soleo.

IMPOSITUS, a, um, adj. - Imposto; aplicado, dado (um nome); colocado. Nomen impositum: nome dado. Herba imposita persanat $(\mathrm{Pa})$ : a erva aplicada cura completamente. Nomen specificum haud recte impositum: nome específico dado sem razão. Sori dorso impositi (FB): os soros colocados no dorso. Cf. adultero, citra, contusus, infundibuliformis, nomen, plumula, rotatus.

IMPRESSUS, a, um, adj. - Afundado; visível sem formar relevo. Nervis secundariis impressis (FB): com as nervuras laterais planas (não elevadas sobre a superfície) ou impressas. Cf. plagula, rete, sed.

IMPRIMIS, adv. - Principalmente, sobretudo; em primeiro lugar; inicialmente. Plantas Brasilienses imprimis observavi: observei principalmente as plantas brasileiras. Cf. discrimen, foetor, methodicus.

IMPRIMO, imprimitur, imprimerentur - Imprimir, comprimir. Dum hae plagellae im- 
primerentur (FB): enquanto estas folhas eram impressas. Cf. compressus, depressus.

IMPROBUS, a, um, adj. - Desleal, desonesto, mal. Segundo Lp., por metáfora: planta aculeada.

IMPROPRIE, adv. - Impropriamente. Cf. qualibet.

IMUM, imi, subs. $n$. 2 - $\mathrm{O}$ fundo, a parte mais baixa. Rami ab imo usque ad cacumem (M): os ramos, desde a base até o ápice (desde o fundo até a ponta). Cf. imus (mais usado em Botânica).

IMUS, ima, imum, adj. - $O$ que se acha mais em baixo ou no fundo de algo. Imus apex: a extremidade do ápice. Ima basi: na extrema base. Folia ima basi cuneata: as folhas cuneiformes na porção mais baixa da base. In ima corolla: no fundo da corola. Stamina imo perigonii tubo inserta (FB): os estames inseridos no fundo do tubo do perigônio. Cf. exserens, ille, petalum, spelunca.

IN, prep. com acus. e abl. - Em, dentro de, durante; a, para, até. Folium in apice acutum: a folha aguda no ápice. Parasiticus in ramis arborum: parasito sobre os ramos das árvores. Filamenta in annulum connata: os filetes soldados em anel. Folia colore in flavum languido (M): folhas de cor amarela esmaecida. Caule in purpuram vergente (M): com o caule tendendo para a cor púrpura. Novembri in Januarium floret (FB): floresce de novembro até janeiro. Cf. a, ac, agnosco, bifidus, circa, consulendus, conversus, decurrens, dehiscens, desinens, divisus, floreo, flos, inclinans, lanceolatus, liana, lignum, manipulus, masculus, modus, nonnisi, nuper, pandens, praelectio, provenio, que, redactus, superius, tamen, tectum, tenidens, virens.

INACCURATUS, a, um, adj. - Descuidado. Descriptio inaccurata (FB): descrição mal cuidada, inexata.

INAEQUALIS, e, adj. - Desigual; heterogêneo; variável. Foliis basi inaequalibus (FB): com folhas desiguais na base (uma das metades maior ou menor do que a outra). Cf. crenatus, lacer, praemorsus, scaber.

INAEQUALITAS, atis, subs. f. 3 - Desigualdade. Absque omni inaequalitate (Lp): sem qualquer desigualdade. Cf. scaber.

INANIS, e, adj. - Vazio, oco. Pollinis granula florum hermaphroditorum inania, collapsa (FB): os grãos de pólen das flores hermafroditas são vazios, murchos.

INAPERTUS, a, um, adj. - Fechado. Cf. tuber.

INARTICULATUS, a, um, adj. - Não articulado. Cf. acerosus.

INCANUS, a, um, adj. - Branco bolorento. Folia incana (Lp): como tomentosa, mas de cor esbranquiçada. Cf. cinereus.

INCARCERATUS, a, um, adj. - Encerrado dentro de. Lineolis incarcerata (Lp): encerrado por linhas.

INCENDIUM, i, subs. n. 2 - Incêndio; queimada dos campos. Cf. cito (adv.). 
INCEPTUS, a, um, adj. - Começado,iniciado; planejado. Incepta a Tournefortio (Lp): iniciada por Tournefort.

INCERTUS, a, um, adj. - Incerto, duvidoso. Incertae sedis (FB): de posição duvidosa. Cf. ideo, species, vagus.

INCESSO, incesserunt - Avançar, atacar, ameaçar. Varii hanc viam incesserunt (Lp): vários lançaram-se neste caminho.

INCHOARE - Começar, iniciar. Novam vitam inchoare (Lp): iniciar uma vida nova.

INCHOATUS, a, um, adj. - Começado, iniciado. Stylus inchoatus: estilete mal desenvolvido, imperfeito.

INCIDENS, incidentis, adj. - Que se fixa, prende.

INCIPIENS, incipientis, adj. - Que começa. Cf. terminans.

INCIPIO, incipit, incepere (= inceperunt) - Começar; empreender. Adeoque incepere ab algis (Lp): e, por isso, começaram pelas algas. Cf. mensis.

INCISIO, onis, subs. f. 3 - Incisão. Cf. ploro.

INCISURA, ae, subs. f. 1 - Recorte. Cf. dissectus, praemorsus.

INCISUS, a, um, adj. - Cortado, seccionado. Segundo Lp: sinônimo de laciniatus.

INCLEMENTIA, ae, subs. f. 1 - Inclemência; dureza; rigor. Cf. clima.

INCLINANS, inclinantis, adj. - Que se inclina; que tende. Foliis colore ex viridi in luteum inclinante (M): com as folhas de cor verde tendendo para o amarelo. Flores miniati ad violaceum inclinantes $(\mathrm{M})$ : as flores são vermelhas com tonalidade violácea.

INCLUDENS, includentis, adj. - Que encerra, inclui. Stamina germenque includens (Lp): que inclui os estames e o ovário. Cf. digestus.

INCLUDO, includit - Encerrar, fechar. Adeoque essentialem includit (Lp): e por isso encerra o essencial.

INCLUSUS, a, um, adj. - Incluído, escondido no interior de. Hymenium excipulo thallove inclusum: himênio incluído no excípulo ou no talo. Folia incluso petiolo $6 \mathrm{~cm}$ longo ad $25 \mathrm{~cm}$ longa (FB): as folhas têm até $25 \mathrm{~cm}$ de comprimento incluindo o pecíolo de $6 \mathrm{~cm}$. Cf. uncia.

INCOGNITUS, a, um, adj. - Desconhecido. Planta veteribus, quantum reor, incognita (M): planta, tanto quanto penso, desconhecida dos antigos. Flores adhuc incogniti (FB): as flores até agora desconhecidas. Cf. antiquus, exemplum.

INCOLA, ae, subs. m. e f. 1 - Habitante, nativo de. Forma adjetivos como: arboricola, saxicola, rupicola, etc. "Pinheiro" ab incolis nuncupata (FB): chamada pinheiro pelos habitantes. Brasiliae aequatorialis incola (FB): habitante do Brasil equatorial. Incolae 
fructibus vescuntur (FB): os nativos alimentam-se com os frutos. Cf. appellatus, appello, nuncupatus, turgeo, vescor.

INCOLENS, incolentis, adj. - Que habitam, que vivem, etc. Arbores Cubam incolentes: árvores que vivem em Cuba. Aliisque circum flum. Purus incolentibus (FB): e por outros que habitam em torno do rio Purus.

INCOLO, incolunt, incolit - Habitar, viver. Omnes Americam incolunt (FB): todas habitam a América. Praeterea incolit Guatemalam (FB): além disso, vive na Guatemala.

INCOMBUSTIBILIS, e, adj. - Incombustível. Frustula Diatomacearum indole sua silicea incombustibilia: os corpos das Diatomáceas não queimam por sua natureza silicosa.

INCOMPARABILIS, e, adj. - Incomparável. Segundo Lp como metáfora: para designar planta muito grande. Opus incomparabile (Lh): obra incomparável.

INCOMPLETE, adv. - Incompletamente. Cf. at.

INCOMPLETUS, a, um, adj. - Incompleto. Flor: sem cálice ou corola (L). Cf. apetalus.

INCONSPICUUS, a, um, adj. - Não saliente; inconspícuo, pouco aparente. Cf. arcus.

INCORRUPTUS, a, um, adj. - Não corrompido. Cf. consto.

INCRASSATUS, a, um, adj. - Engrossado, espessado. Incrassati versus florem pedicelli (Lp): pedicelos engrossados na direção das flores. Membrana incrassata: membrana espessada. Cf. e, mirus, ob, ope, suffultus, ve.

INCREBER, ra, rum, adj. - Ralo; delgado; frouxo. Thallus increber aut sat creber: 0 talo frouxo ou bastante compacto. Apothecia increbra: os apotécios laxos. Em ambos os exemplos refere-se à estrutura.

INCREMENTUM, $\mathbf{i}$, subs. n. 2 - Incremento, aumento, crescimento. Scapus ingens et celerrimi incrementi (FB): o escapo é muito grande e de rapidíssimo crescimento. Cf. habitabilis, processus.

INCRETUS, a, um, adj. - Espalhado, misturado. Paraphyses cum ascis incretae: as paráfises misturadas com os ascos.

INCUMBENS, incumbentis, adj. - Que se deita sobre o solo. Segundo Lp: o mesmo que versatilis, quanto à antera. Antera: presa pelo filete lateralmente. Cotyledones incumbentes: quando o caulículo (hipocótilo, radícula) aplica-se sobre o dorso de um dos cotilédones. Folia aquae incumbentia (FB): as folhas são aplicadas à água.

INCUMBO, incumbit, incumbunt - Deitar-se, apoiar-se. Quorum apicibus antherae incumbunt (Lp): sobre as pontas dos quais as anteras apoiam-se. Cf. natans.

INCURIA, ae, subs. f. 1 - Incúria, desleixo, negligência, descuido. Cf. pictor.

INCURVUS, a, um, adj. - Dobrado para dentro. O mesmo que inflexus e incurvatus. Cf. corniculum. 
INDAGATOR, oris, subs. m. 3 - Indagador, investigador. Rei plantariae indagator acerrimus (M): profundo investigador da Botânica.

INDE, adv. - De lá; desde (inde a ou ab.): por isso. Iam inde a principio: já desde o início. Inde liquet quod calyx (Lp): por isso é evidente que o cálice. Petalum inde a basi angustatum: a pétala estreitada desde a base. Cellulae inde a $150 \mathrm{X}$ notatae: as células visíveis desde 150 aumentos. Rhizoma hinc inde vaginis praeditum (FB): o rizoma possui bainhas aqui e ali. Cf. canaliculatus, dissitus, emergens, emigratus, hinc, methodicus, microscopium, sejunctus, usque.

INDEFATIGATUS, a, um, adj. - Infatigável. Cf. detector.

INDEFESSUS, a, um, adj. - Incansável. Ubi indefessus Glaziou nuperius eam detexit (FB): onde a descobriu, há pouco, o incansável Glaziou.

INDEFINITUS, a, um, adj. - Indefinido. Cf. numerus.

INDESCRIPTUS, a, um, adj. - Não descrito. Cf. species.

INDETERMINATE, adv. - Indeterminadamente. Cf. laciniatus.

INDEX, indicis, subs. m. e f. 3 - Indice; catálogo. Iconum botanicarum index: índice das ilustrações botânicas. Index nominum plantarum multilinguis (Lh): índice, em muitas línguas, dos nomes de plantas. Index Herbariorum: índice dos herbários. Cf. genericus, locuples, multilinguis, opus.

INDIA, ae, subs. f. 1 - India. Ex Indiis Occidentalibus allata (M): trazida das Índias Ocidentais. Cf. advectus, obtulit, petrosus.

INDIANI, orum, subs. m. pl. 2 - Os índios. Nomen Indianorum "murumuru" (FB): o nome dos índios é murumuru.

INDICATIO, onis, subs. f. 3 - Indicação. Cf. habitatio.

INDICATUS, a, um, adj. - Indicado, denunciado, revelado. Cf. discrimen, i, lectus, versus.

INDICO, indicavi, indicat, indicatur - Indicar, denunciar, revelar. Frutescentem indicat plantam caule teretiusculo: mostra uma planta arbustiva com caule subcilíndrico. Cf. abortus, dissertatio, omissus, quoties.

INDICUS, a, um, adj. - Da Índia, indiano. Cf. exemplum, frumentum.

INDIGENA, ae, subs. m. 1 - Indígena, natural da região, nativo. Também adj. m. f. e n. Plantae indigenae (Lp): plantas nativas, autóctones. Nominibus indigenis (Lp): com nomes indígenas, do país de origem. Brasiliae est indigena:é nativo no Brasil. In sagittarum usum convertunt indigenae (FB): os indígenas empregam para flechas. Cf. existimo, factus, nomen.

INDIGENUS, a, um, adj. - Indígena, nativo. In Asia tropica indigenum (FB): nativo na Ásia tropical. 
INDISTINCTUS, a, um, adj. - Indistinto; confuso. Nervi indistincti: nervuras indistintas, inconspícuas, pouco aparentes.

INDITUS, a, um, adj. - Indicado, revelado, estabelecido. Secundum generationis inditas leges (Lp): de acordo com as leis estabelecidas da reprodução.

INDIVIDUUM, $\mathbf{i}$, subs. $n$. 2 - Indivíduo, a verdadeira unidade taxionômica (nas plantas superiores sexualmente propagadas). Occurrunt, quamvis rarius, individua dimidio minora (FB): aparecem, embora um tanto raramente, indivíduos com metade do tamanho habitual.

INDIVIDUUS, a, um, adj. - Indivíduo, indiviso, inteiro, íntegro. Folium individuum (M): folha inteira. Cf. fascia.

INDIVISUS, a, um, adj. - $\mathrm{O}$ mesmo que individuus, porém, mais usado. Folia indivisa: folhas indivisas, íntegras. Cf. frons.

INDOLES, is, subs. f. 3 - Natureza, índole; estrutura. Ex indole: por natureza. Folia ex indole ovalia: as folhas são ovais por natureza. Indole florum haud commutanda: pela natureza das flores não deve ser confundida. Etiam pollinis indoles characteristica est (FB): também é característica a índole do pólen. Ovula ejusdem omnino indolis ac in praecedente (FB): os óvulos são inteiramente da mesma natureza do que na anterior. Cf. discrepo, incombustibilis, situs, stabilitus.

INDUBITANTER, adv. - Indubitavelmente. Cf. ius.

INDUCO, inducis - Puxar sobre; estender sobre, cobrir de alguma coisa. Cf. linteolum.

INDUCTUS, a, um, adj. - Posto sobre, aplicado; revestido, coberto; introduzido. Inductus epidermide (Lp): revestido por uma epiderme. Sucus expressus est de penna inductus $(\mathrm{Pa})$ : o suco expremido e aplicado por meio de uma pena.

INDUMENTUM, $\mathbf{i}$, subs. $n$. 2 - Indumento, revestimento das plantas, de origem epidérmica (pêlos, escamas, glândulas, acúleos, etc.). Capsula indumento varie vestita (FB): a cápsula variadamente recoberta pelo indumento. Cf. conferendus, densus, ferrugineus, vestitus.

INDUO, induit, induunt, induuntur - Vestir, cobrir-se, assumir. Ibi folia saepe colorem induunt (Lp): ai as folhas, com freqüência, tomam cor. Cf. coloratus, viscum.

INDURATUS, a, um, adj. - Endurecido; congelado. Ad eos qui induratas venas habent $(\mathrm{Pa})$ : para os que têm veias (artérias) endurecidas. Cf. nullomodo.

INDURO, indurantur - Endurecer, fazer duro; congelar. Quae dein indurantur (Lp): que depois se tornam endurecidas.

INDUS, i, subs. m. 2 - Indio; classicamente: hindú (da India). Indorum Orinocensium, Barré, etc. (FB): dos Indios orinocenses, Barré, etc. Apud Indos Carajas (FB): entre os indios Carajás. 
INDUSIATUS, a, um, adj. - Dotado de indúsio. Semina placenta pulposa indusiata (FB): as sementes recobertas pela placenta polposa.

INDUSIUM, i, subs. n. 2 - Indúsio. Cf. discissus, obverse, pronascens, textura.

INDUSTRIA, ae, subs, f. 1 - Atividade, aplicação, esforço. Cf. absolvo.

INDUTUS, us, subs. m. 4 - Vestido, indumento; o vestir. Cf. lanatus.

INDUVIA, ae, subs. f. 1 - Induviae: restos do cálice, corola ou androceu que persistem em torno do fruto, mas sem aderência. Podem crescer com o ovário ou permanecer em estado seco. Fructus induviis plus minusve auctis suffultus (FB): o fruto apoiado no perianto persistente e mais ou menos ampliado. Cf. ex.

INEO, inest, insum - Entrar, penetrar; formar; haver. Radix inest Iridi candidans, solida (M): há, em Iris, raiz branca, maciça. Cf. triangularis.

INERMIS, e, adj. - Desarmado, sem espinhos, etc. Inerme spinoso folio opponitur (Lp): (a folha) inerme opõe-se à folha espinhosa.

INEXPLICATUS, a, um, adj. - Não completamente desenvolvido, jovem, fechado. Folia inexplicata (FB).

INFALLIBILIS, e, adj. - Infalível. Nullus character infallibilis est (Lp): nenhum caráter é infalivel.

INFANTIA, ae, subs. f. 1 - Infância. Linné: nas plantas.

INFARCTUS, a, um, adj. - Túrgido, intumescido.

INFECUNDUS, a, um, adj. - Infecundo, estéril.

INFERIOR, comp. m. e f. de inferus - Inferior, mais baixo. Folia inferiora parva: as folhas inferiores pequenas. Cf. carnosus, cuneiformis, dimidiatus, ellipticus, fio, lyratus, radicans, reclinatus, subulatus, superficies.

INFERIUS, comp. $n$. de inferus - Inferior, mais baixo. Também adv. Cf. declinatus, emoriens, labium.

INFERNE, adv. - Inferiormente. Folia inferne alterna (Lp): as folhas inferiormente alternas. Cf. desinens, dolabriformis, lyratus, panduraeformis, tortus.

INFERNUS, a, um, adj. - Colocado em baixo, na porção inferior.

INFERUS, a, um, adj. - $O$ mesmo que infernus. Radícula: quando se dirige para a base da semente. Ovarium inferum: ovário ínfero. Cf. germen.

INFICIO, inficit - Impregnar; tingir, colorar. Cf. caput.

INFIGO, infigitur - Fincar, pregar. Rostellum infigitur calyci plantae (Lp): o rostelo prende-se ao cálice da planta. 
INFIMUS, a, um, adj. - Superl. de inferus. Ínfimo, o mais baixo entre todos. Cf. appendix, decurrens, fibra.

INFINITUS, a, um, adj. - Infinito, ilimitado; indeterminado. Crescit in infinitum (Lp): cresce indefinidamente. Cf. ens, species, varietas.

INFIXUS, a, um, adj. - Fixado, preso, inserido. Caudices ope radicum terrae infixi: os estirpes fixados ao solo por meio das raízes.

INFLATIO, onis, subs. f. 3 - Flatulência; aumentar o volume soprando, enchendo de ar. Fabae inflationem habent: as favas produzem flatulência. Inflatione, ut volumen laevius evadat (Lp): aumentando o volume com espaços vazios, de modo que o movimento se torne mais fácil (transporte das sementes através do ar).

INFLATUS, a, um, adj. - Inflado, dilatado. Pericarpium inflatum cum instar vesicae cavum fit (Lp): o pericarpo é inflado quando se torna oco como bolha. Cf. urceolatus.

INFLECTENDUS, a, um, adj. - Que deve ser dobrado, vergado, curvado. Non vero inflectendae (Lp): realmente, não devem ser dobradas.

INFLEXUS, a, um, adj. - Curvado, com a curvatura, porém, voltada para dentro. Inflexus si versus plantam sursum arcuetur (Lh): (a folha) é inflexa quando se curva para acima, em direção à planta. Isto é, o ápice foliar voltado para dentro. Prefoliação infletida: o limbo da folha dobra-se transversalmente, ficando a mesma voltada para dentro.

INFLORESCENTIA, ae, subs. f. 1 - Inflorescência. Antigo: modus florendi. Inflorescentia est modus, quo flores pedunculo plantae annectuntur $(\mathrm{Lp})$ : a inflorescência é o modo pelo qual as flores se inserem no pedúnculo da planta. Cf. ceterum, compositus, efficiens, formatus, modo.

INFLUXUS, us, subs. m. 4 - Influência. Cf. astrologus.

INFOECUNDUS - $O$ mesmo que infecundus. Floribus et fructibus infoecunda (M): estéril pelas flores e pelos frutos.

INFRA, prep. com acus. e adv. - Abaixo, debaixo. Eam alligabis infra talum $(\mathrm{Pa})$ : amarra-la-ás sob o tornozelo. Petala infra scabra (FB): as pétalas, na página inferior, são escabras. Cf. demersus, detrusus, enumeratus, ferens, pulvis.

INFRICO, infrica - Esfregar sobre, aplicar com a friç̧ão. Cf. cinis.

INFUNDIBULIFORMIS, e, adj. - Infundibuliforme, em forma de funil ou trombeta; afunilado. Infundibuliformis, conicus, tubo impositus (Lp): (limbo) infundibuliforme, cônico, colocado sobre tubo. Cf. accedo.

INFUNDO, infundatur - Infundir, derramar, verter. Cf. fistula.

INGENS, ingentis, adj. - Ingente, muito grande. Cf. incrementum. 
INGERO, ingerendorum, ingere - Deitar, derramar; colocar; lançar. Aquam ingere: derrama ou verte água. Ingerere ligna foco: lançar madeira ao fogo. Cf. diaeteticus.

INGRATE, adv. - Desagradavelmente; constrangidamente; com ingratidão. Cf. itidem.

INGRATUS, a, um, adj. - Desagradável; ingrato. Cf. gravis, gustus, sapor.

INGREDIENS, ingredientis, adj. - Que caminha, anda; que entra em alguma coisa, penetra. Raro in zonam temperatam ingredientia (FB): raramente penetrando na zona temperada. Cf. aestus.

INHABITANS, inhabitantis, adj. - Que vive, habita, reside. Gramina intra tropicos inhabitantia (FB): Gramíneas que vivem dentro dos trópicos.

INHABITO, inhabitat - Habitar em, residir em alguma região, etc. Totam Americam inhabitat (FB): vive em toda a América.

INHAERENS, inhaerentis, adj. - Que está preso, pegado, grudado. Baccae pedunculo pertinaciter inhaerentes (M): as bagas estão firmemente fixas ao pedúnculo. Crescit scopulis inhaerens $(\mathrm{FB})$ : vive agarrando-se às pedras.

INHAEREO, inhaeret - Estar preso, agarrado, fixo. Foliis principium amarum inhseset (FB): encerra um princípio amargo nas folhas.

INIENS, ineuntis, adj. - Que começa, que se inicia. Augusto ineunte anthesi (FB): com a antese começando em agosto.

INITIUM, i, subs. n. 2 - Começo, início. Novae plantae facit initium (Lp): dá início d nova planta. Initio rerum (Lp): no início das coisas (que existem). Cf. flos, species.

INJURIA, ae, subs. f. 1 - Injustiça, violação do direito. Ab externis injuriis (Lp): das injúrias exteriores (intempéries). Cf. pubescentia.

INNATO, innatat - Sobrenadar, boiar, flutuar. Superficie aquae innatat (Lp): flutua na superfície da água. Cf. stagnans.

INNATUS, a, um, adj. - Nascido sobre alguma coisa. Species in arboribus proceris innata: espécie nascida sobre árvores altas. Cf. alter, elevatus, palea, spinosus, unus.

INNIXUS, a, um, adj. - Apoiado sobre. Fruticulus humo innixus (FB): arbustinho apoiado sobre o humus.

INNOCUUS (innoxius), a, um, adj. - Inócuo, inofensivo; brando; inocente. Caeteris ruminantium innocua $(\mathbf{M})$ : inofensiva para os demais ruminantes. Cf. pubes.

INNOTESCO, innotuit, innotuissent - Vir a saber-se; tornar-se conhecido, celebrizar-se. Solummodo e vicinia Rio de Janeiro innotuit (FB): chegou ao conhecimento tão somente da vizinhança do Rio de Janeiro. Cf. priusquam.

INNOTUIT - Veja innotesco. 
INNOVATIO, onis, subs. f. 3 - Broto; ramos e folhas muito jovens; ramo novo. Cf. abiens, glandula.

INNOXIUS - Veja innocuus. Cf. fungus.

INNUMERUS, a, um, adj. - Inúmero, inumerável. Innumeris exemplis docuit (Lp): com inúmeros exemplos demonstrou. Cf. sulcatus, virgulta.

INODORUS, a, um, adj. - Inodoro. Radices inodorae (Lp): raízes sem cheiro. Cf. dies, radix.

INOPIA, ae, subs. f. 1 - Falta de qualquer coisa, inópia. Ob characterum inopiam (FB): em razão da ausência de caracteres.

INORDINATE, adv. - Desordenadamente. Ovula inordinate insidentia (FB): os óvulos inserindo-se sem ordem.

INQUAM, inquit - Dizer. Cf. corymbus.

INQUE - In e que: e em, e no, etc. In campis inque silvis: nos campos e nas matas.

INQUILINUS, $\mathbf{i}$, subs. m. 2 - Inquilino. Species unica in Brasilia inquilina (FB): só uma espécie é habitante do Brasil.

INQUIRENDUS, a, um, adj. - $O$ que deve ser procurado, investigado. Cf. fragmentum.

INQUIRENS, inquirentis, adj. - Que procura, investiga. Botanici inquirentes veterum vocabula $(\mathrm{Lp})$ : os botânicos que investigaram os termos usados pelos antigos.

INQUIRO, inquirit - Procurar, investigar. Microscopio structuram inquirit (FB): investiga a estrutura ao microscópio.

INQUISITIO, onis, subs. f. 3 - Pesquisa. In plantarum inquisitione (M): na investigação, ou pesquisa, sobre as plantas.

INSCRIBO, inscribitur - Escrever em ou sobre alguma coisa; intitular. Cf. ovatus.

INSCRIPTUS, a, um, adj. - Escrito; marcado, assinalado; gravado. Lineis tenuissimis inscriptis (Lp): marcado por linhas muito leves. Differentia ipsi plantae inscripta (Lp): diferença assinalada na própria planta. Cf. striatus.

INSCULPTUS, a, um, adj. - Insculpido, com altos e baixos; marcado. Caudex rimulis minutis insculptus: 0 caule marcado por pequeninas fendas.

INSECO, insecat - Cortar. Qui tamen insecat (FB): aquele que, todavia, corta (ao micrótomo).

INSECTA, orum, subs. n. pl. 2 - Os insetos. Cf. caussatus, destructus, magnus, metr morphosis, munitus.

INSEQUENS, insequentis, adj. - Seguinte, próximo, subseqüente. Cf. systematicus. 
INSERO, inseratur, inseritur, inserantur, inseruntur - Inserir, prender, fincar, cravar; introduzir. Receptaculo communiter inseruntur (Lp): com freqüência, prendem-se ao receptáculo. Cf. axillaris, fundus, locus, obovatus, peltatus, radicalis, respectus, sparsus, stellatus.

INSERTIO, onis, subs. f. 3 - Inserção, maneira pela qual algo se prende em alguma coisa; enxertia. Insertio foliorum consideratur ex modo, quo folio plantae adnectitur (Lh): a inserção das folhas considera-se segundo a maneira pela qual a folha prende-se à planta. Insertio folii fit basi ejusdem (Lp): a inserção da folha diz respeito à base da mesma. Insertiones medullares: raios medulares. Cf. situs.

INSERTUS, a, um, adj. - Inserido; introduzido. Petalis insertis receptaculo (Lp): com as pétalas inseridas no receptáculo. Filamenta unguibus petalorum inserta (Lp): os filetes inseridos nas unhas das pétalas. Cf. axilla, basis, confertim, excavatio, imus, interdum, secundum, supremus.

INSERVIENS, inservientis, adj. - Que serve. Et tenello tegendo fovendoque inserviens $(\mathrm{Lp})$ : tanto servindo para cobrir como para proteger o que há de mais delicado (na flor). Characteres specierum distinctioni inservientes (FB): caracteres que servem para a distinção das espécies.

INSERVIO, inservit - Servir. Canon inservit tyroni (Lp): a regra aplica-se ao principiante. Cujus usui inservit (Lp): a cujo uso se destina.

INSIDENS, insidentis, adj. - Que está colocado, inserido, etc. Floribus cupulae bractearum insidentibus: com as flores colocadas sobre a cúpula das brácteas. Caudici insidens (Lp): situado sobre o eixo da raiz. Stamina germini insidentia (Lp): os estames inseridos sobre o ovário. Cf. arista, inordinate, parum.

INSIDO, insidet, insideat - Fixar-se, inserir-se, enraizar-se. Quae cauli insidet (Lp): que se insere no caule. Cf. communiter, patens, rameus, ramus, retusus, vaginans.

INSIGNIS, e, adj. - Notável, distinto; que chama a atenção; belo. Datura insignis: nome dado em razão das belas e grandes flores, que a tornam uma espécie bem distinta das demais. Colore et figura, vel utroque insignis (Lp): é distinta pela cor e forma, ou por anbos. Cf. congener, conjunctus, decore, demissus, discolor, fertilitas, minus.

INSIGNITER, adv. - Notavelmente, distintamente. Structura insigniter discedit (FB): distingui-se notavelmente pela estrutura.

INSIGNITUS, a, um, adj. - Notável, distinto; marcado; manifesto. Specimen, hoc nomine insignitum (FB): um exemplar, determinado com este nome. Tribus numero et situ ovulorum insignita (FB): a tribo é distinta pelo número e posição dos óvulos.

INSIPIDUS, a, um, adj. - Insípido.

INSITIO, onis, subs. f. 3 - Enxertia. Locus insitionis (FB): o ponto de contacto (entre parasito e hospedeiro, etc.).

INSPECTIO, onis, subs. f. 3 - Exame, estudo. Cf. congener. 
INSPECTUS, a, um, adj. - Examinado, estudado. Plantme exsiccatae inspectae: plantas secas examinadas. Cf. exemplar, insuper.

INSPERSUS, a, um, adj. - Espalhado, borrifado; recoberto, revestido. Folia pilis glandulosis inspersa (FB): as folhas borrifadas com pêlos glandulosos. Cf. aliquis.

INSTAR, indecl. - Como, à maneira de; exige gen. Folia instar corollae velutina: as folhas aveludadas como a corola. Aculeata instar juniperi (M): aculeada como o zimbro. Rami vitilium instar (M): os ramos como vime. Instar viae ad Botanicen ducit (Lp): conduz à Botânica como uma estrada. Folia repetite pinnata instar Leguminosarum (FB): as folhas repetidamente penadas à maneira das Leguminosas. Cf. funis, inflatus, tortilis, urceolatus.

INSTINCTUS, us, subs. m. 4 - Impulso, incitação; inspiração; instinto. Naturalis instinctus docet nosse (Lp): um impulso natural leva a ter conhecido.

INSTITUO, instituit - Estabelecer; proceder, etc. Quae species et varietates instituit (Lp): a qual estabelece as espécies e as variedades. Cf. chemicus (adj.), primus.

INSTITUTIO, onis, subs. f. 3 - Arranjo, disposição; método. Institutiones rei herbariae: os princípios da Botânica (obra de Tournefort).

INSTITUTOR, is, subs. m. 3 - Instrutor. Institutores regulas et canones composuerunt: os instrutores instituiram regras e leis.

INSTRATUS, a, um, adj. - Jazer sobre, estar deitado. Cf. repens.

INSTRUCTUS, a, um, adj. - Provido de, aparelhado com. Ramosus est ramis lateralibus instructus (Lp): ramoso é (o caule) dotado de ramos laterais. Folia apice mucrone instructa (FB): as folhas providas de mucrão no ápice. Antherae utrinque appendiculis instructae (FB): as anteras são dotadas de apêndices pequenos em ambos os lados. $\mathrm{Cf}$. acumen, appendix, duplex, foliatus, lumen, oleifer, singuli, subter, tuba.

INSTRUO, instruxerunt, instruitur, instruuntur - Colocar, possuir; estudar. Umbellatorum classem instruxerunt (Lp): estudaram a classe das Umbeladas (=Umbelliferae). Petiolis propriis instruuntur (Lp): são dotadas de pecíolos próprios. Calycibus flores instruuntur (Lp): as flores são providas de cálice. Cujus basis instruitur gluma (Lp): cuja base é ornada de gluma. Cf. calyx, deltoidis, quoque.

INSULA, ae, subs. f. 3 - Ilha. Ex insulis Bahamensibus: das Ihas Bahamas. Insula Marajo: a ilha de Marajó. In insulis Trinitatis (FB): nas Ithas Trindade. Cf. enumeratio, pacificus, syllabus.

INSUPER, adv. - Além disso, ao demais; de cima, por cima. Folia lente vitreorum insuper inspecta: as folhas examinadas, com lente, por cima. Numero staminum insuper peculiaris (FB): além disso, é distinto pelo número dos estames.

INTACTUS, a, um, adj. - Não tocado, intacto. Intacto disco folii (Lp): estando inteiro o limbo da folha (abl. abs.).

INTEGER, gra, grum, adj. - Indiviso, integro. Integer sinubus omnibus caret (Lh): a 
folha íntegra, ou inteira, é destituída de quaisquer recortes (seios). Diz respeito ao limbo, embora a margem possa ser recortada. Cf. discus, haereo, integerrimus, sinus, vel.

INTEGERRIMUS, ma, mum, adj. - Superl. de integer. Muito inteiro. Integrum probe distinguendum ab integerrimum ( $\mathrm{Lh}$ ): (a folha) íntegra deve ser perfeitamente distinguida de integérrima. Refere-se às margens; o limbo, nas folhas integérrimas, pode ser recortado, mas não a margem.

INTEGUMENTUM, $i$, subs. n. 2 - Cobertura, tegumento. Segundo Lp.: córtex, da raiz, p. ex. De integumento seminis: sobre o tegumento da semente. Cf. dum, duplex, quum.

INTELLECTUS, a, um, adj. - Compreendido, etc. Hisce intellectis (Lp): tendo sido compreendidos estes (fatos). Abl. abs. Também subs. m. 4 Inteligência; significação.

INTELLIGIBILIS, e, adj. - Compreensível. Cf. vegetabilis.

INTELLIGO, intelligunt, intelligitur, intelliguntur, intelligit - Perceber, compreender, entender; saber. Flores intelliguntur ex dictis (Lp): as flores são compreendidas pelo que foi dito anteriormente. Qui de systemate nihil intelligit (Lp): que nada entende acerca do sistema. Cf. botanicus, primario.

INTER, pron. com acus. - Entre; por entre, no meio de; dentre. Arbor inter omnes altissima: a árvore mais alta entre todas (a árvore mais alta). Cf. alius, botanicus (adj.), cohaerens, congener, dentatus, differentia, distinctio, emicans, flora, flumen, insignis, itaque, lacer, lapis, ludo, papyrus, philyra, plurimus, ponendus, rictus, scilicet, signator, sequor, spatium, tegens, versor.

INTERCEDO, intercedant - Estar entre, estar no meio. Cf. sulcatus.

INTERCEPTUS, a, um, adj. - Interceptado, interrompido. Rami geniculis intercepti (M): os ramos interrompidos por nós. Nec articulis interceptus (Lp): não interrompido por articulações. Cf. geniculus.

INTERCLUSUS, a, um, adj. - Fechado; impedido. Nisi omnes aliae interclusae sint viae (Lp): a menos que estejam interditos todos os outros caminhos.

INTERDIU, adv. - De dia, durante o dia. Flores nocte vel etiam interdiu expansi (FB): as flores abrem à noite ou também durante o dia.

INTERDUM, adv. - Às vezes, de vez em quando. Calyci inserta interdum (Lp): às vezes, inseridos no cálice. Folia oblonga interdum ovalia: as folhas oblongas, às vezes ovais. Cf. decolor, liana, linearis, fortuitus.

INTERIM, adv. - Entretanto; por enquanto; às vezes. Cui ad interim nomen adscribimus (FB): à qual demos o nome provisoriamente.

INTERIOR, comp. m. e f. de intra. Interior, mais para dentro. Cf. exterior, pedatus, raphides.

INTERIORA, orum, subs. n. pl. 2 - 0 interior. Paulum in interiora invadens (FB): que 
penetra pouco no interior. Cf. vitans.

INTERIUS, comp. $\mathrm{n}$. de intra - Interior, mais para dentro. Também adv.: interiormente. Cf. exterius.

INTERJACENS, interjacentis, adj. - Que está no meio, que está de permeio. Cf. sinuatus.

INTERJECTUS, a, um, adj. - Colocado entre. Stamina 4, laciniis interjectis nullis: estames 4, sem lacínias interpostas. Ut interjecta substantia (Lp): de modo que a substância intercalada. His interjecta sunt (Lp): há, colocados entre estes. Pars geniculis duobus interjecta (Lp): parte situada entre dois nós. Cf. is, oppositus, repandus, totidem.

INTERMEDIUS, a, um, adj. - Intermédio; intermediário, colocado entre duas espécies ou extremos. Cf. conjunctus.

INTERMIXTUS, a, um, adj. - Misturado, colocado entre. Granula fertilia cum sterilibus intermixta (FB): grãos férteis misturados com estéreis.

INTERNE, adv. - Internamente. Cf. cavitas, obvestio, repletus, tubulosus.

INTERNODIUM, i, subs. n. 2 - Entrenó, meritalo. Rami internodiis $3 \mathrm{~cm}$ longis (FB): os ramos com entrenós medindo $3 \mathrm{~cm}$ no comprimento. Petioli internodiis breviores: os pecíolos mais curtos do que os entrenós. Cf. accretus, usque, vagina.

INTERNUS, a, um, adj. - Interno, interior. Cf. anatomicus, columella.

INTERPETIOLARIS, e, adj. - Colocado entre pecíolos opostos. Stipulae interpetiolares: estípulas interpeciolares.

INTERPRES, interpretis, subs. m. e f. 3 - Intérprete. Interprete Saraceno: pelo intérprete Saracenus (com a interpretação de).

INTERRUPTE, adv. - Com interrup̧̧ões. Cf. pinnatus.

INTERSECTUS, a, um, adj. - Dividido, cortado. Triplici vel quadruplici lacinio intersecto (M): dividido por três ou quatro lacínias.

INTERSTINCTUS, a, um, adj. - Colocado, marcado; variegado. Per particulas rite interstinctas (Lp): por meio da pontuação corretamente colocada. Petioli septis transversis interstincti (FB): os pecíolos riscados por septos transversais.

INTERSTITIUM, ii, subs. n. 2 - Interstício, intervalo. Interstitiis inter florum glomerulos 1-2 cm longis: com os intervalos entre os glomérulos de flores medindo $1-2 \mathrm{~cm}$ no comprimento. Cf. dissitus.

INTERTEXTUS, a, um, adj. - Entretecido, entrelaçado; entremeado. Villis intertextis (Lp): por pêlos entrelaçados.

INTERVALLUM, i, subs. n. 2 - Intervalo, distância em geral. Cf. ambitus. 
INTESSELATUS, a, um, adj. - Quadriculado. Cf. connexus.

INTIMUS, ma, mum, adj. - Superl. de intra: o mais interno.

INTINCTUS, a, um, adj. - Molhado, posto na água. Cf. aridus.

INTORSIO, onis, subs. f. 3 - Intorsio est flexio partium versus alterum latus (LP): intorsio é a curvatura ou torsão das partes para outro lado.

INTORTUS, a, um, adj. - Torcido; enrolado. Folliculi corniculi modo intorti (M): os frutos enroscados como pequeno chifre.

INTRA, adv. e prep. - Por dentro. Intra paucas horas discutiet et postea ejiciet $(\mathrm{Pa})$ : dentro de poucas horas aliviará e, em seguida, eliminará (para fora do corpo). Intra florem (Lp): no interior da flor. Calyx intra forisque velutinus: o cálice velutino por dentro e por fora. Cf. carnosus, caro, colloco, corculum, enatus, inhabitans, maximus, membranaceus, partitio.

INTRAMARGINALIS, e, adj. - Intramarginal. Cf. arcus.

INTRAPETIOLARIS, e, adj. - Colocado dentro da axila. Stipulae intrapetiolares.

INTRANS, intrantis, adj. - Que penetra. Fascibus per hilum intrantibus (FB): com os feixes que penetram pelo hilo.

INTRARIUS, a, um, adj. - Penetrante. Embryo intrarius (FB): embrião que penetra (no albumen).

INTRICATUS, a, um, adj. - Enredado, embaraçado; intrincado, entrelaçado. Medulla ex hyphis laxiuscule intricatis formata: a medula formada por hifas algo frouxamente entrelaçadas. De hoc genere intricatissimo (FB): a respeito deste oênero muito complicado.

INTRO, intrare, intret, intrabat, intrarent - Entrar, penetrar em. Qu. intrabat semina foecunda (Lp): que penetrava nas sementes fecundadas. Ne intret cohortem notarum (Lp): não entre no conjunto dos caracteres. Cf. credo, maeandrus, nequeo, petiolatus.

INTRODUCO, introduxit - Introduzir, mandar entrar; levar para dentro. Plantam in Europam introduxit cl. Linden (FB): o ilustre Linden introduziu a planta na Europa.

INTRODUCTIO, onis, subs. f. 3 - Introdução, admissão. Introductio in Botanicen (Lh): Introdução à (ao estudo da) Botânica. De hujus speciei introductione in Brasiliam (FB): acerca da introdução desta espécie no Brasil.

INTRODUCTUS, a, um, adj. - Introduzido. Cf. nuper.

INTROFLEXUS, a, um, adj. - Infletido, dobrado para dentro. Valvae marginibus introflexae: as valvas são infletidas por seus bordos.

INTRORSUM, adv. - Para dentro; dentro, por dentro, interiormente. Silvam longe in- 
trorsum pertinere: que uma floresta penetrava pela terra a dentro a longa distância. Cf. acinaciformis.

INTUITUS, us, subs. m. 4 - Intenção; vista de olhos, o olhar, vista. Usado só em abl. Primo intuitu (Lp): à primeira vista, sem maior consideração, imediatamente. Primo intuitu distinguit Botanicus plantas $(\mathrm{Lp})$ : o botânico distingüe as plantas à primeira inspeção. Ut primo intuitu typo eandem diceret (Lh): que, à primeira vista, dir-se-ia a mesma pelo tipo.

INTUMESCENS, intumescentis, adj. - Que incha, que se torna túmido.

INTUMESCO, intumescit - Inchar-se, entumescer; crescer, aumentar-se. Pericarpium intumescit et extenditur $(\mathrm{Lp})$ : o pericarpo aumenta e se expande.

INTUS, adv. - Dentro, para dentro, interiormente. Corolla intus glabrata: a corola mais ou menos glabra por dentro. Cf. cavus, extus, farctus, habens, latus, medulla.

INTUS, prep. com acus. e gen. - Dentro de, para, em. Intus apotheciorum: dentro dos apotécios.

INUNDATUS, a, um, adj. - Inundado, algado. Segundo Lp: local cheio de água durante certo tempo (subs.). Silva inundata: floresta inundada. Inundatae: plantas que crescem na água (subs. pl.) Cf. degens, obrepo, recens.

INUSITATUS, a, um, adj. - Raro, fora do comum; desusado. Artificium veteribus inusitatum (Lp): o sistema (de desenhar) dos antigos está fora de uso. Cf. liana.

INVADENS, invadentis, adj. - Que entra, penetra em, invade alguma coisa. Cf. interiora.

INVENIO, invenitur - Achar, encontrar. In cedro arbore invenitur (M): encontra-se sobre o cedro. Cf. raro, tanicus.

INVENTIO, onis, subs. f. 3 - Achado; descobrimento. Inventionem eius Mercurio assignat $(\mathrm{Pa})$ : atribui a descoberta dela a Mercúrio.

INVENTOR, oris, subs. m. 3 - Descobridor, autor, inventor. Primus huiusce plantae inventor (M): o primeiro descobridor desta planta.

INVENTUM, i, subs. n. 2 - Invento, invenção. Cf. recens.

INVERSUS, a, um, adj. - Inverso, invertido. Semente: quando sua base corresponde ao ápice do ovário. Animal inversum: animal às avessas, como os antigos concebiam a planta. Cf. suus.

INVESTIENS, investientis, adj. - Que envolve. Cf. vaginans.

INVESTIGANDUS, $\mathbf{a}$, um, adj. - $\mathrm{O}$ que deve ser investigado, indagado. Cf. peregrinator. 
INVESTIGATIO, onis, subs. f. 3 - Indagação, investigação. Investigationibus futuris commendo (FB): recomendo às pesquisas futuras. Cf. anatomicus (adj.).

INVESTIGO, investigavit - Procurar, indagar, investigar; descobrir. Pilulariae flores investigavit Jussiaeus (Lp): Jussieu investigou as flores de Pilularia.

INVICEM, adv. - Alternadamente, reciprocamente. Ab invicem: reciprocamente, cada um por sua vez; alternadamente. Ut invicem se tegant (Lp): de modo que se cubram reciprocamente (umas às outras). Tamen characteribus sat firmis ab invicem posse distingui (FB): contudo, pode ser distinguida uma da outra por caracteres bastante sólidos. Cf. capillamentum, complicatus, imbricatus.

INVISUS, a, um, adj. - Não visto, invisível, oculto. Colonis invisa (Lp): prejudicial aos lavradores.

INVIUS, a, um, adj. - Impraticável, intransitável, inacessível. Nascitur in inviis locis (M): ocorre em lugares inacessiveis.

INVOLUCRUM, i, subs. n. 2 - Invólucro (geralmente chama-se invólucro a muitas brácteas reunidas para proteção das flores), cobertura (de brácteas, etc.). Linné: brácteas das umbelas. Antigo: envoltório. Cf. facies, monophyllus, quisque.

INVOLUTUS, ta, tum, adj. - Involuto. Prefoliação involuta (Lp): quando as margens da folha se enrolam em direção à página superior. Cf. circinatim, lana.

INVOLVO, involvitur, involvat - Envolver, enrolar, cobrir de. Ab eodem involvitur (Lp): é envolvido pelo mesmo. Perianthium involvat receptaculum $(\mathrm{Lp})$ : o perianto envolve o receptáculo.

IODUM, i, subs. n. 2 - Iodo. Cf. reagens, vinose.

IPSE, ipsa, ipsum, adj. - O mesmo, a mesma; ele, ela mesmo (refere-se ao próprio sujeito). Ego ipse: eu mesmo. Est virtus ipsa: é a própria virtude. Bracteae sub calyce ipso prodeuntes: as brácteas saindo debaixo do próprio cálice (= inseridos sob o ...). Operum ..., haec ipse vidi et consului: Das obras ...., estas eu mesmo vi e consultei. Et ipsa folia mastices $(\mathrm{Pa})$ : e masques as próprias folhas. Punctum vitae ipsius plantae (Lp): é o ponto da própria vida da planta. Ergo ipse prodit e depactis ramis (Lp): por consequêencia, a mesma (flor) se origina de ramos enterrados. Natura ipsa sociat et conjungit lapides et plantas (Lp): a própria natureza associa e une as pedras com as plantas. Cf. cooperio, discus, inscriptus, liberalitas, locus, opus, peltatus, prodiens, que, sinistrorsus, tellus, undulatus.

IRIS, iridis, subs. f. 3 - Iris (planta); gênero. Iridiflorus: com flores parecidas com as de iris. Cf. inest, nomen, sativus.

IRREGULARIS, e, adj. - Irregular. Antigo: anomalus, difformis. Cf. papilionaceus, ringens.

IRREGULARITAS, atis, subs. f. 3 - Irregularidade. Cf. caussor. 
IRREGULARITER, adv. - Irregularmente. Cf. contextus (adj.), disrumpens.

IRRIGUUS, a, um, adj. - Banhado, molhado. Cf. locus, scopulum.

IS, ea, id, pron. - Aquele, aquela; o mesmo, a mesma; o, a. Gen. sing.: eius. Et ex eo in ore tenes $(\mathrm{Pa})$ : e retenhas, na boca, uma porção do mesmo. Quae ob id Achillea vocatur $(\mathrm{Pa})$ : a qual, por isso, chama-se Achillea. Graeci eam dicunt $(\mathrm{Pa})$ : os gregos chamam-na de. Alia item herba similis est ei $(\mathrm{Pa})$ : existe outra erva, da mesma natureza, semelhante a ela. Eisque interjectis sinubus (Lp): aos quais interpõem-se seios. Dicitur is flos, qui (Lp): denomina-se a flor que. Quam ii crediderant (Lp): do que eles acreditaram. Colore ab ea distinguitur: distingue-se dela pela cor. Est forma inter eas media (FB): é uma forma intermediária. Cum axis continuatione vel sine ea (FB): com o prolongamento do eixo ou sem ele. Cf. a, aedificium, brevi, cingens, crenatus, cum, dabo, e, earum, eis, ejus, ex, iis, igitur, ius, maxime, medicus, nudus, ob, plurimum, sed, sulcatus, summus, unde, velut.

ISAGOGAE (isagoge), arum, subs. grego f. pl. 1 - Rudimentos, elementos, primeiras lições. Isagoge in rem Herbariam (Lh): Elementos de Botânica. Isagoge phytoscopica: manual de Botânica.

ISIDIUM, i, subs. n. 2 - Isídio, produção das camadas cortical e gonidial na superfície dos líquens. Thallus isidiis destitutus: o talo desprovido de isídios. Cf. soredium.

ISOMERUS, a, um, adj. - Com igual número de partes (em relação a outro). Stamina isomera (FB).

ISOSTEMONEUS, a, um, adj. - Isostêmones. Flor: com estames em número igual ao de pétalas. Flores isostemonei (FB).

ISTE, ista, istud, pron. e adj. - Esse, essa, isso. Gen. sing. istius, pl. istorum, istarum, istorum. Multae istarum arborum: muitas destas árvores. Multae ex istis arboribus: como $o$ anterior. Proxima isti (FB): próxima desta. Cf. pictus.

ISTHMUS, i, subs. m. 2 - Istmo, o que liga duas partes. Sed isthmo gelatinoso concatenata: mas encadeadas por istmo gelatinoso.

ISTIUS - Gen. sing. de iste, ista, istud.

ISTORUM, istarum, istorum - Gen. pl. de iste, ista, istud.

ITA, adv. - Assim, deste modo. Expletiva. Ita ut superiores majores sint (Lp): de maneira que os superiores sejam maiores. Cum ita copiosa, ut ramos occupent totos $(\mathrm{Lp})$ : quando são tão numerosas que ocupam os ramos todos. Cf. directio, ius, luxurians, persisto, procul, spinosus, unda, unio, ut.

ITALIA, ae, subs. f. 1 - Itália. Cf. advena, frequens, gummi, pharmacopola, provenio.

ITALICUS, a, um, adj. - Da Itália. Cf. lingua.

ITAQUE, adv. - E assim; logo, portanto. Vai em primeiro lugar na frase. Itaque inter 
sese admodum affinis: posto isto, são muito afins entre si. Cf. factus, mihi, praesto, scandens, sinistrorsus, superfluus.

ITEM, adv. - Da mesma forma; da mesma natureza; igualmente. Herba item dabis ut supra $(\mathrm{Pa})$ : darás a erva do mesmo modo como acima. Floribus item glandulosis: com as flores igualmente glandulosas. Foliola floralia non item (Lp): as folhinhas florais não (se comportam) da mesma forma. Item per Guianas disseminata (FB): igualmente espalhada pelas Guianas. Cf. is.

ITER, itineris, subs. n. 3 - Viagem, jornada. Ad iter faciendum (Pa): para viajar (para fazer uma viagem). Iter Brasiliense: viagem ao Brasil. Itinera per Helvetiae alpinas regiones $(\mathrm{Lh})$ : viagens pelas regiões alpinas da Suiça. Cf. pretiosus.

ITERUM, adv. - Pela segunda vez, mais uma vez. Iterum atque iterum ou iterum iterumque: muitas vezes, freqüentemente. Cf. examen.

ITIDEM, adv. - Da mesma forma, igualmente. Itidem ingrate olent (Lp): do mesmo modo, cheiram desagradavelmente. Cf. laciniatus.

ITINERA - Veja iter.

IULI, iulorum, subs. n. pl. 2 - Inflorescência frutificada das betuláceas. Emittit iulos corylaceis fere similes (M): emite casulos algo semelhantes aos da aveleira. Cf. absimilis.

IULIUS (julius), a, um, adj. - Referente ao mês de julho. Cf. floreo.

IULUS, $i$, subs. m. 2 - Veja o plural iuli.

IUS, iuris, subs. n. 3 - Caldo, sopa. Et ita ius earum bibitur (Pa): e, assim, beba-se o caldo delas.

IUS, iuris (jus), subs. n. 3 - Direito, justiça. Species indubitanter sui iuris (FB): espécie sem dúvida independente (ou: sui juris). Cf. genus.

JACIO, jecit - Atirar, lançar; levantar, construir. Hujus fundamenta jecit (Lp): lançou as bases deste.

JACTURA, ae, subs. f. 1 - Perda, prejuízo; despesas; sacrifício. Opus quo carere potest orbis absque jactura (Lh): obra da qual pode privar-se o mundo sem prejuízo.

JAM (iam), adv. - Já, neste momento. Jam floribus $10 \mathrm{~cm}$ longis statim recognoscitur: reconhece-se imediatamente já pelas flores com $10 \mathrm{~cm}$ de comprimento.

JAMDUDUM, adv. - Há já muito tempo, há tempos; prontamente, sem demora, logo; etc. Jamdudum inter omnes constat (FB): já há muito tempo é do conhecimento de todos. 
JANEIRENSIS, e, adj. - 0 mesmo que fluminensis. Provincia Janeirensis (FB): o Rio de Janeiro.

JANUARIUS, a, um, adj. - Relativo ao mês de Janeiro. Januarius mensis: janeiro.

JANUARIUS, i, subs. m. 2 - Janeiro (mês). Flumen Januarii: Rio de Janeiro. Cf. in, sanctus.

JUCUNDUS (iucundus), a, um, adj. - Agradável, ameno, alegre; amável. Floribus aspectu iucundis $(\mathrm{M})$ : com flores de agradável aspecto (= aos olhos).

JUDICIUM, ii, subs. n. 2 - Juízo; opinião, parecer. Meo judicio (FB): no meu entender, segundo penso.

JUDICO, judicare - Julgar, opinar, etc. Cf. licet (verbo).

JUGLANS, dis, subs. f. 3 - Nogueira; noz desta árvore. Cf. absimilis.

JUGUM, i, subs. n. 2 - Par; duas folhas ou folíolos colocados lado a lado. Folia ejusdem jugi (FB): as folhas do mesmo par. Folia unijuga, bijuga, trijuga, 5-juga, etc.: folhas com $1,2,3,5$, etc., pares de folíolos, até multijuga.

JULUS, i, subs. m. 2 - Cf. amentum.

JUMENTUM (iumentis), i, subs. n. 2 - Animal de carga. Cf. mortifer.

JUNCTIO, onis, subs. f. 3 - Junção, ponto de encontro ou reunião. Habitat ad junctionem Orenoci et Rio Negro (FB): vive na junção do Orenoco com o Rio Negro.

JUNGO, junxit, jungit - Unir; fundir. Haec varietas C. hirtum cum C. glandulosum omnino jungit (FB): esta variedade une inteiramente $C$. hirtus com $C$. glandulosus. $C$. quicum.

JUNIOR, oris, comp. de juvenis - Mais novo, jovem, recente. N. sing.: junius. Legumem junius vidi (FB): vi o legume novo. Cf. ego, ramusculus.

JUNIPERUS, i, subs. f. 2 - Junípero ou zimbro (arbusto). Cf. instar.

JUNIUS, a, um, adj. - Relativo ao mês de junho.

JUNIUS, i, subs. m. 2 - Junho. Cf. circa (adv.).

JUS, juris, subs. n. 3 - Veja ius (2). Varietates a viribus publici juris factae (FB): variedades feitas por homens de competência reconhecida. Cf. doctor, natura.

JUSSIAEUS, i, subs. m. 2 - Jussieu, botânico francês. Cf. investigo.

JUSTO, abl. sing. de justus usado como adv. Descriptio justo longior (Lp): uma descrição maior do que o conveniente. Breviores justo evadunt (Lp): tornam-se menores do que o necessário. 
JUVENCULUS, a, um, adj. - Dim. de juventus. Fortasse status juvenculus speciei antecedentis (FB): talvez um estado jovem da espécie anterior.

JUVENTUS, utis, subs. f. 3 - Mocidade; juventude. Sporangia juventute brunnea (FB): os esporângios são pardos quando novos.

JUVO, juvant - Ajudar; servir. Imbres, aestus juvant (Lp): as chuvas, o calor ajudam.

JUXTA (iuxta), prep. com acus. - Bem perto de, ao lado de; sobre; conforme. Também. adv. Habitat ad loca arenosa juxta mare in Gavea (FB): vive em lugares arenosos, junto ao mar, na Gávea. Cf. portus, scaturigo.

\section{$\mathbf{K}$}

KERMESINUS, a, um, adj. - Carmesim, cor vermelha viva. Margine kermesino (FB): com a margem carmesim. Lineolis kermesino-atris (FB): com linhazinhas carmesim de tonalidade escura.

LABELLUM, i, subs. n. 2 - Dim. de labium, lábio: labelo (pétala). Cf. mesidium, more.

LABIATUS - Veja bilabiatus. Cf. ringens, vel.

LABIUM, i, subs. n. 2 - Lábio. Labium superius, inferius: o lábio superior, inferior. Limbi labium lineare: o limbo com lábio linear. Cf. cunnus, fornicatus, rictus, ringens.

LABOR, oris, subs. m. 3 - Trabalho. Per fere annum impigerrimo labore (Lh): com um trabalho intensíssimo de quase um ano. Opus immensi laboris (Lh): obra muitíssimo trabalhosa.

LABORO, laborarunt - Trabalhar, esforçar-se. Cf. methodicus.

LAC, lactis, subs. n. 3 - Leite; látex das plantas. Baccas tritas ex lacte caprino desinit dolor $(\mathrm{Pa})$ : com as bagas moidas com leite de cabra cessa a dor. Cf. cuius.

LACCA, ae, subs. f. 1 - Laca. Cf. provenio.

LACER, ra, rum, adj. - Rasgado, dilacerado. Undique lacerus (Lp): recortado em toda a volta. Lacerum cujus margo segmentis confertis inter se inaequalibus et difformibus constat (Lh): (folha) lacerada, cuja margem consta de segmentos desiguais entre si, densos, e deformados. As reentrâncias marginais são, de todo, desordenadas. Nas folhas laciniadas o limbo é que é subdividido, em lobos muito estreitos; nas laceradas, a mar- 
gem apenas. Disso resulta que uma folha laciniada poderá ser, ao mesmo tempo, lacerada; mas a reciproca não se verifica. Corolla lacera (Lp): limbo finamente recortado. Cf. laciniatus.

LACINIA, ae, subs. f. 1 - Lacínia, segmento. Preferido ao neutro. Calycis laciniae: os segmentos do cálice. Cf. adscendens, alternans, attamen, calycinus, lacinium, lyratus, pinnatifidus.

LACINIATUS, a, um, adj. - Laciniado. Folha: irregularmente recortada. Segundo Lp: o mesmo que incisa ou dissecta. Laciniatum varie sectum in partes, partibus itidem indeterminate subdivisis (Lp): (a folha) laciniada é dividida em partes, sendo estas, igualmente, subdivididas sem ordem. Laciniatum quod sinus plures ad medium folii pertingentes, lobis subdivisis, admittit (Lh): (a folha) laciniada é a que mostra seios numerosos, alcançando o meio da folha, com lobos subdivididos. Nesse caso, os segmentos são muito estreitos e compridos. Cf. multifidus.

LACINIUM, $i$, subs. $n$. 2 - 0 mesmo que lacinia, este quase sempre empregado em Botânica. Cf. intersectus, qui.

LACINULUS, i, subs. m. 2 - Dim. de lacinium. Cf. obsessus.

LACTESCENS, lactescentis, adj. - Latescente, leitoso, que contém látex. Plantae lactescentes (Lp):

LACTESCENTIA, ae, subs. f. 1 - Lactescência. Lactescentia est copia liquoris, qui effluit laesa planta (Lp): a lactescência é a quantidade de líquido que escapa quando a planta é ferida.

LACTEUS, a, um, adj. - Lácteo, de leite, branco como tal. Cf. albus, madens, succus, turgeo.

LACTIFER, a, um, adj. - Que gera leite, dotado de suco leitoso. Lactiflorus: com flores leitosas (na cor). Cf. alo, cotyledon.

LACTUCA, ae, subs. f. 1 - Alface. Cf. femina, sumptus.

LACUNA (laguna), ae, subs. f. 1 - Cova, buraco; cavidade; lagoa; lacuna. Cf. oleifer.

LACUNOSUS, a, um, adj. - Com orifícios, cavidades; lacunoso. Cf. paluster.

LACUS, us, subs. M. 4 - Lago, lagoa. Ubi lacus quodam tempore siccantur (M): onde os lagos dessecam-se em certas ocasiões. Habitat in margine lacuum (FB): vive na margem dos lagos. Ad lacum Jacarepagua (FB): na lagoa de Jacarepaguá. Cf. provenio.

LACUSTRIS, e, adj. - Segundo Lp: com águas paradas e profundas.

LAESIO, onis, subs. f. 3 - Ferimento, lesão. Cf. spinosus.

LAESUS, a, um, adj. - Ferido; lesado. Cf. lactescentia, signator. 
LAETUS, a, um, adj. - Brilhante, vívido; alegre, agradável; abundante, fecundo. Laeta pascua (Lp): pasto agradável. In silvis primaevis laetius viget (FB): vegeta mais viçosamente nas florestas virgens.

LAEVIGATUS (levigatus), a, um, adj. - Liso, polido. Excipulum subtus laevigatum: o excípulo é liso na parte inferior.

LAEVIS, e, adj. - Liso, polido. Cf. causa, glaber, inflatio, praefert, supra.

LAGUNA - Veja lacuna. Laguna Sancta (FB): Lagoa Santa.

LAMELLA, ae, subs. f. 1 - Pequena lâmina, lamela. Cf. epidermis, palea, squamosus.

LAMINA, ae, subs. f. 1 - Limbo da folha, da corola. Linné: parte superior, alargada, das pétalas livres. Anatomia: lâmina média. Cf. creber, textura.

LANA, ae, subs. f. 1 - Indumento como penugem ou veludo. Segundo DC: pêlos longos, macios, deitados ou entrecruzados, lembrando a lã. Ramuli in lana involuti $(\mathrm{Pa})$ : os raminhos enrolados em lã. Lana servat plantas ab aestu nimio (Lp): a lã protege as plantas contra o calor excessivo.

LANATUS, a, um, adj. - Lanoso (pêlos compridos e crespos, como os de lâ). Lanatum quasi tela araneae indutum (Lp): (a folha) lanada é como se fôsse revestida por teia de aranha.

LANCEOLATUS, a, um, adj. - Lanceolado. Lanceolatum est oblongum, utrinque attenuatum a medio ad extremum in apicem (Lp): (a folha) lanceolada é oblonga, mas estreitada para ambos os lados, do meio em direção às extremidades, em ponta. 0 comprimento supera até 4 vezes a largura, base e ápice agudos. Quando bem larga, a folha será: oblongo-lanceolata ou late lanceolata (largamente lanceolada). Se bem estreita: lanceolato-linearia ou lineari-lanceolata (linear-lanceolada), que ainda, poder-se-á chamar anguste lanceolata: estreitamente lanceolada. Cf. acinaciformis, ex, ovato-lanceolatus.

LANGUIDUS, a, um, adj. - Cansado; vagaroso; indolente; negligente. Cf. in.

LANIGER, a, um, adj. - Produtor de lã, coberto de lã. O mesmo que lanatus. Cf. pilosus.

LANUGINEUS, a, um, adj. - Lanuginoso. Lanugineum caulem nutriunt (M): produzem caule lanuginoso.

LANUGO, uginis, subs. f. 3 - 0 mesmo que lana. Spinosa prorsus lanugine obducuntur urticae caules $(\mathrm{M})$ : os ramos da urtiga são inteiramente revestidos por uma pilosidade espinhosa. Molli lanugine pubescens (Lp): pilosa com lanosidade macia (vilosa). Cf. obductus.

LAPIDETUS, a, um, adj. - Veja lapidosus. Cf. fere.

LAPIDEUS, a, um, adj. - De pedra. Cf. naturalia. 
LAPIDOSUS, a, um, adj. - Pedregoso, lapidoso. 0 mesmo que lapidetus. Loca lapidosa $(\mathrm{Pa})$ : lugares cheios de pedra.

LAPIS, idis, subs. m. 3 - Pedra. Praesertim inter muscosos lapides (M): principalmente entre pedras cobertas de musgos. Lapides crescunt (Lp): as rochas crescem. Lapis lazuli: ultramar (cor azul). Cf. discrimen, ipse.

LAPPONICUS, a, um, adj. - Da Lapônia (Europa). Flora Lapponica (obra de Linné).

LAPSUS, lapsus, subs. m. 4 - Queda; falta, delito. Aperto lapsu: por um engano manifesto, evidente. Cf. calamus.

LARGE, adv. - Abundantemente, largamente. O mesmo que largiter. Ramis ad nodos large fasciculatim emergentibus (FB): com os ramos saindo abundantemente dos nós sob a forma de fascículos.

LARGIENS, largientis, adj. - Que fornece, distribui, dá. In drupis oleum largiens (FB): que fornece óleo nas drupas.

LARGIOR, largiri - Distribuir; dar, fornecer, conceder. Fructus oleum largiri dicuntur (FB): dizem que os frutos fornecem óleo.

LARGITER, adv. - Veja large. Haud largiter tributae esse videntur (FB): não parecem ser largamente distribuídas.

LARIX, icis, subs. f. 3 - Conífera, sorte de pinheiro: lariço. Cf. agaricum, mano, Plinius.

LATE, adv. - Largamente. Longe lateque: por toda parte. Superl.: latissime. Folia late elliptica: folha largamente elíptica. Cf. diffusus, dispersus, lanceolatus.

LATEO, latet, latent, latuisse - Faltar; estar escondido; ser ignorado. Capsula latet (FB): a cápsula acha-se ausente. Semina in fructibus latent (FB): as sementes faltam nos frutos. Capsula auctoribus hucusque latuisse videtur (FB): a cápsula parece ter escapado até agora aos autores.

LATERALIS, e, adj. - Lateral. Nervi laterales: nervuras laterais (secundárias, terciárias, etc.). Cf. coeo, cotyledon, decem, instructus, papilionaceus, triangularis.

LATESCENS, latescentis, adj. - Latescente, que encerra látex; neologismo erudito derivado de látex, laticis. Vasa latescentia: tubo laticífero ou laticífero simplesmente. Cf. lactescens (oriundo de lac, lactis, forma clássica).

LATET, latent - Veja lateo.

LATEX, laticis, subs. m. 3 - Látex, líquido espesso, geralmente alvo, que dimana após ferimento em numerosas plantas. Cf. latice.

LATICE - Veja latex. Latice copioso, flavo: com látex abundante, amarelo. 
LATICIFER, a, um, adj. - Laticífero. Fasciculi fibrovasculares laticiferis instructi (FB): os feixes fibrovasculares providos de laticíferos.

LATINUS, a, um, adj. - Latino. Latinus sermo: latim. Nomina generica latinis literis pinguenda sunt (Lp): os nomes genéricos devem ser transcritos com letras latinas. $C f$. conversus, lingua, nuncupo.

LATIOR, latius - Com. de latus: mais largo. Cf. foemina, panduraeformis, undulatus.

LATITUDO, udinis, subs. f. 3 - Largura. Cf. aegre, ellipticus, ubique.

LATUS, a, um, adj. - Largo, amplo, grande, extenso. Folia $3 \mathrm{~cm}$ lata (FB): as folhas têm $3 \mathrm{~cm}$ na largura. Folia fere pollicem lata (FB): as folhas com quase 1 polegada de largura. Cf. abditus, mucronatum, origo, pandens, quam.

LATUS, lateris, subs. n. 3 - Lado; flanco. Latera ne confundantur cum angulo (Lh): não sejam os lados confundidos com o ângulo. Flos a latere: flor (vista) de lado. Carpella intus et a latere visa: os carpelos vistos por dentro e de lado. Ad latus germinis (Lp): ao lado do ovário. Ad latera viae (FB): nas margens da estrada. Cf. acinaciformis, amplexicaulis, aversus, bipinnatus, compressus, depressus, fuere, hastatus, margo, panduraeformis, pedatus, pinnatifidus, sinuatus, trigonus, triquetrus, uterque.

LAUDABILIS, e, adj. - Louvável, digno de louvor. Haec herba tam laudabilis ut in theriacis et potionibus mittatur $(\mathrm{Pa})$ : esta erva é tão renomada que se prescreve em teriagas e em poções.

LAUDATUS, a, um, adj. - Citado, chamado, mencionado. Species nomine Cassiae javanicae laudata:a espécie citada pelo nome de Cassia Javanica. Sub nomine Struthanthi laudatus (FB): mencionado com o nome de Struthanthus. Praeter autores laudatos (FB): além dos autores citados. Cf. auctor, decus.

LAUDO, laudat, laudant, laudatur, laudantur - Louvar; aprovar; citar, alegar. Laudo hanc plantam Cyphisiae: chamo a esta planta de Cyphisia. Cf. e.

LAURINUS, a, um, adj. - De louro (Laurus nobilis L.), laurino. Cf. coactus, oleum.

LAURUS, i ou us, subs. f. 2 ou 4 - Loureiro. Laurus tam tenuifolia quam latifolia arbor est (M): o loureiro tanto é árvore tenuifolia como latifolia.

LAVO, lavato - Lavar, banhar. Cf. corpus.

LAXE, adv. - Frouxamente. Cf. paraphysis.

LAXIUSCULE, adv. - Dim. de laxe. Cf. intricatus.

LAXUS, a, um, adj. - Laxo, frouxo, espalhado, aberto. Cf. aquosus. 
LECTOR, oris, subs. m. 3 - Leitor. Lectori Botanico; benevolo, etc.: ao leitor botânico; benévolo, etc. $\mathrm{Cf}$. benevolus.

LECTUS, a, um, adj. - Seleto; escolhido; colhido. Ab. A. Ducke lecta, loco natali haud indicato: colhida por A. Ducke, não tendo sido indicada a localidade natal. Lectus in silva ad S. Paulo a Martio (FB): colhido na mata, em S. Paulo, por Martius. Fructus non lecti (FB): os frutos não (foram) colhidos. Cf. cementum, consortium, hucusque, scaturigo, tesqua, via, viator.

LEGITIME, adv. - Normalmente, regularmente. Cf. efformatus.

LEGO, legis, legit, lege, legere, legerunt, legimus - Colher, juntar; ler; recitar. Legit Brade n. 24: colheu Brade n. 24. Legerunt Ducke et C. Porto: colheram Ducke e C. Porto. Falso Ourouparea legitur (FB): lê-se, erradamente, Ourouparea. Cf. apud, maxime, mensis, mundus, tempus.

LEGUMEN, uminis, subs. n. 3 - Legume (todas as acepções), vagem. Legumen, pericarpium bivalve, affigens semina secundum suturam alteram tantum (Lp): o legume, pericarpo que insere sementes ao longo de uma sutura apenas. Legumina omnia singulas habent radices $(\mathrm{P})$ : todos os legumes possuem uma raiz. $\mathrm{Cf}$. ideo.

LENIS, e, adj. - Branda, suave; moderado. Cf. anhelitus, medulla.

LENS, tis, subs. f. 3 - Lente; lentilha (planta): Herbam cum lente coquito (Pa): cozinhe a erva com lentilha. Leno vitretisrum efficatia: a eficiência da lente de vidro. $C$ f. insuper.

LENTE, adv. ou abl. de lens - Cf. subulatus.

LENTICELLA, ae, subs. f. 1 - Lenticelas ou lentículas, produções de tecido suberoso frouxo formando pequenas saliências; são aberturas que substituem os estômatos da epiderme primária.

LENTICELLIGER, a, um, adj. - Que produz ou possui lenticelas ou lentículas. Rami lenticelliger (FB).

LENTICELLOSUS, a, um, adj. - Lenticeloso. Cf. haud.

LENTUS, a, um, adj. - Flexível, tenaz. Cf. medulla, surculosus.

LEPIDOIDEUS, a, um, adj. - $O$ mesmo que lepidotus. Cf. glandula.

LEPIDOTUS, a, um, adj. - Dotado de escamas. Indumentum lepidotum (FB).

LEPIS, dis, subs. f. 3 - 0 mesmo que squama.

LEPORINUS, a, um, adj. - Leporino. Segundo Lp., como metáfora: espécie que se agita como a lebre.

LEPROSUS, a, um, adj. - Leproso, caspento. Foliis glabris subtus leprosis: com as folhas glabras, na página inferior com indumento que lembra caspa. 
LEPUS, leporis, subs. m. e f. 3 - Lebre. Cf. tremens.

LETHALIS (letalis), e, adj. - Letal, mortal. Cf. venenum.

LEVIGATUS - Veja laevigatus.

LEVIS, e, adj. - Leve, ligeiro. Cf. curo, distraho, nota, momentum, scrobiculum.

LEVISSIME, adv. - Superl. de leviter: levissimamente, o mais levemente possível.

LEVITER, adv. - Levemente, ligeiramente. Cf. notatus.

LEVIUS, adv. - Comp. de leviter: mais levemente. Ainda nom. sing. n. de levior. Stamina levius ad corollam adnata: os estames mais levemente soldados à corola.

LEX, legis, subs. f. 3 - Lei; regra; qualidade, índole. Cf. ars, inditus, natura, physiologus.

LEXICOGRAPHUS, i, subs. m. 2 - Lexicógrafo. Lexicographi nomina diversarum linguarum colligunt (Lp): os lexicógrafos (dicionaristas) recolhem os termos de diversas línguas.

LEXICON, i, subs. n. 2 - Léxico, dicionário. Lexicon polyglotton (vocabulário poliglota) $=$ index multilinguis. Magnum Lexicon: Grande Dicionário.

LIANA, ae, subs. f. 1 - Liana, termo de Eichler para as plantas trepadeiras lenhosas, aqui em geral ditas cipós. Quales plantas nomine lianarum salutamus (FB): damos a tais plantas o nome de lianas. Quae in funes vegetabiles, tupice cip6, in opere nostro interdum lianas vocatos, inusitatae formae, excrescunt (FB): as quais crescem enormemente em cordas vegetais, em tupi chamadas cipos, em a nossa obra por vezes ditas lianas, de forma fora do comum.

LIBER, ra, rum, adj. - Livre; independente. Ovarium liberum: ovário livre ou súpero (= ovarium superum). Placentatio centralis libera: placentação central livre; os óvulos estão sobre um eixo mediano livre na cavidade do ovário.

LIBER, bri, subs. m. 2 - Livro; liber das plantas ou floema; casca interna. Pro pueris non Botanicis pictus liber (Lh): um livro ilustrado em cores para crianças, não para botânicos. Liber constat ex cellulis, fibris vasisque (FB): o liber consta de células, fibras e vasos. Cellulae libri: as células do floema. Cf. bibliotheca, botanicus, compono, cruciatus, deinde, huius, prelum, productus, qui, quoque, tamen.

LIBERALITAS, atis, subs. f. 3 - Cortesia, bondade; generosidade. Cujus specimina ipsius auctoris liberalitati debeo (FB): cujos exemplares devo à generosidade do próprio autor.

LIBERATUS, a, um, adj. - Desembaraçado. Semen pericarpio liberatum FB): semente desembaraçada do pericarpo.

LIBERE, adv. - Livremente. Cf. desumptus. 
LICET, conj. - Ainda que, embora. Vegetabilia, sensatione licet destituantur (Lp): os vegetais, embora sejam desprovidos de sensação. Licet colorem floris ignoremus (FB): embora ignoremos a cor da flor. Cf. alo, efformatus, gradus, huic, resolvo, solummodo.

LICET - Ser lícito, ser permitido a alguém. Nomen genericum dignum, alio licet aptiore, permutare non licet (Lh): não se deve trocar um nome genérico conveniente, mesmo por outro mais apto. Quam cum M. elegante coincidere judicare licet (FB): a que é lícito supor que coincida com M. elegans.

LICHEN, enis, subs. m. 3 - Líquen. Antigo: Marchantia. Lichenibus tuberculum est (Lp): o tubérculo nos líquens, é. Cf. crustaceus, dorsiventralis.

LIGATUS, a, um, adj. - Amarrado, atado. Cf. collum.

LIGNEUS, a, um, adj. - De madeira. Cuius color est ligneus cinericius (M): cuja cor lembra a de madeira, com tonalidade acinzentada. Planta lignea: planta lenhosa. Corpus ligneum, lignea portio: o lenho ou xilema. Strata ou involucra lignea: anéis de crescimento. Cf. vas.

LIGNINUM, i, subs. n. 2 - Lignina.

LIGNOSUS, a, um, adj. - Lenhoso, provido de madeira ou lenho secundário. Radix est lignosa, ramosa: a raiz é lenhosa, ramificada. Cf. corpus, frutescens, radix.

LIGNUM, i, subs. n. 2 - Madeira, lenho. Lignum secundarium: lenho secundário. Ligno ad constructionem haud spernendo: a madeira não é desprezável para construção. Herba contusa de ligno in ligno vel iligno $(\mathrm{Pa})$ : a erva pisada com madeira, em recipiente de madeira ou carvalho. Cf. arca, crassivenius, compono, enodis, estructura, materies, paro, secedens, spina.

LIGULA, ae, subs. f. 1 - Lígula. Gramíneas: rebordo membranáceo ou piloso entre a bainha e a lâmina das folhas. Zingiberáceas: prolongamento do conectivo acima da antera. Compostas: flor periférica em forma de língua. Cf. solutus.

LIGULATUS, a, um, adj. - Ligulado, dotado de lígula ou com tal forma. Tipo de corola. Ligulati (= semiflosculosi) (Lp): flores liguladas do capítulo das Compostas. Cf. planipetalus.

LILIUM, i, subs. n. 2 - Lírio. Cf. propago.

LIMBUS, i, subs. m. 2 - Limbo. Segundo Linné: parte superior, dilatada, da corola "monopétala". Até princípio do século XIX só se aplicava à corola. Cf. connivens, decurrens, desinens, labium, margo, ob.

LIMES, mitis, subs. m. 3 - Limite, atalho; caminho. Cf. debeo, determino, pono.

LIMITATIO, onis, subs. f. 3 - Delimitação. De familiae limitatione (FB): acerca da delimitação da família.

LIMOSUS, a, um, adj. - De localidade enlameada; lodoso; que vive no lodo, etc. Fundo limoso (Lp): com fundo limoso. In solo limoso (FB): no solo limoso. 
LIMPIDUS, a, um, adj. - Límpido. Cf. mox.

LINEA, ae, subs. f. 1 - Linha, traço, fio; medida linear. Linea est lunulae longitudo (Lp): a linha é o comprimento da lúnula (crescente lunar localizado na raiz das unhas). Cerca de $2 \mathrm{~mm}$. Igual a 12 capilli e à 12. a parte da polegada parisiense. Sepala 4 lineas longa: as sépalas com $8 \mathrm{~mm}$ no comprimento. Cf. desino, discretus, duodecimus, extimus, inscriptus, striatus, truncatus.

LINEALIS, e, adj. - Linear. Stipite ultrasemilineali (FB): com o estipe (medindo) além de meia linha.

LINEARI-LANCEOLATUS, a, um, adj. - Linear-lanceolado ou estreitamente lanceolado (= anguste lanceolatus); a folha é fina, como linear, mas as duas margens são convexas (e não paralelas) e as extremidades agudas. Cf. lanceolatus.

LINEARIS, e, adj. - Linear, que mede uma linha. Petioli bilineares: os pecíolos com 2 linhas $(4 \mathrm{~mm})$. Lineare utraque extremitate saepius attenuatur, marginibus vero secundum longitudinem aequali spatio distantibus et parallelis (Lh): (a folha) linear é estreitada, freqüentemente, em ambas as extremidades, com as margens, ao longo do comprimento, mantendo igual espaço entre si e paralelas. Interdum utraque extremitate tantum angustatur (Lp): às vezes, estreita-se apenas nas duas extremidades. Cf. fissus, labium, linguiformis, ludo, spathulatus, subulatus.

LINEATUS, a, um, adj. - Marcado por linhas ou listas; riscado. Vasa lineata: vasos escalariformes $\mathrm{e}$ anelados.

LINEOLA, ae, subs. f. 1 - Dim. de linea. Cf. incarceratus.

LINGUA, ae, subs. f. 1 - Língua (órgão); palavra; língua (idioma); linguagem. Latina, Gallica, Lusitanica, Italica, etc., língua: língua latina, francesa, portuguesa, italiana, etc. In lingua generali (FB): em língua geral (tupi). Cf. conversus, distinctio, excalfaciens, lexicographus, subjectus, translatus, usitatus.

LINGUIFORMIS, e, adj. - Linguiforme, com a forma de língua. Linguiformis est lineare, obtusum, carnosum, depressum, subtus convexum, margine saepius cartilagineum (Lh): (a folha) linguiforme é linear, obtusa, carnosa, deprimida, convexa na página inferior, freqüentemente cartilaginosa na margem.

LINNAEUS, Linnaei, subs. m. 2 - Nome alatinado de Kar von Linné (também: Carolus a Linne e Carolus Linnaeus). Entre nós, vulgarizou-se a forma Lineu, procedente da latina. Viveu, na Suécia, entre 1707 e 1778, sendo o fundador da moderna Biologia. De Candolle recomenda as suas obras como modelos de linguagem científica (taxonomia). Linnaea: nome de um gênero e de uma velha revista de Botânica. Tabula affinitatum plantarum secundum ordines Linnaei: tabela das afinidades das plantas segundo as ordens de Linné. Cf. praelectio, scientia.

LINNEANUS, a, um, adj. - Relativo a Linnaeus. Planta Linneana (FB).

LINTEOLUM, i, subs. n. 2 - Lenço (de linho). Inducis linteolo grosso (Pa): colocas em lenço espesso. Cf. madidus. 
LINUM, i, subs. n. 2 - Linho (planta); linho (fio ou tecido). Cf. pollen, quis.

LIQUAMEN, inis, subs. n. 3 - Mistura líquida, sumo exprimido, molho. Cf. balneus.

LIQUESCENS, liquescentis, adj. - Que se torna líquido; que se liquefaz; que se desfaz. Fructus parietibus dein liquescentibus (FB): o fruto com paredes que mais tarde se desagregam.

LIQUEO, liquet - Ser claro, patente, etc. Cf. esse, inde.

LIQUIDUM, i, subs. n. 2 - Água. Liquida: os líquidos. Ponderum et mensurarum liquidorum ratio (M): cálculo dos pesos e medidas dos líquidos.

LIQUOR, oris, subs. m. 3 - Estado líquido, fluidez; qualquer líquido. Cf. appropriatus, colliquamentum, lactescentia, veho.

LITERA (littera), ae, subs. f. 1 - Letra; carta. Literae alphabeti (Lp): letras do alfabeto. Cf. latinus, numero.

LITIGO, litigarunt - Brigar, disputar; processar. Cf. eristicus.

LTTORALIS - Veja littoralis.

LITOREUS, a, um, adj. - $O$ mesmo que littoralis.

LITTERA - Veja litera. Glaz. in litt. ad auctorem (FB): Glaziou em carta ao autor.

LITTERATURA, ae, subs. f. 1 - Alfabeto; escrito; literatura. Cf. repertorium, thesaurus.

LITTORA - Nom. pl. de littus.

LITTORALIS (litoralis), e, adj. - Que vive no litoral, na costa marítima. Cf. scopulosus.

LITTUS (litus), oris, subs. f. 3 - Praia, costa, litoral. Littora maris (Lp): as praias do mar; a beira-mar. Species valde frequens in littore: a espécie é muito comum na praia. Secus litus orientale (FB): ao longo da costa oriental.

LIVESCENS, livescentis, adj. - Que se torna plúmbeo ou azulado. Folia supra laevia nitidula livescentia: as folhas na face superior são lisas, algo brilhantes e azuladas.

LIVIDE, adv. - Palidamente. Caulis livide viridis (FB): caule palidamente verde.

LIVIDUS, a, um, adj. - Lívido, azulado; cor de chumbo. Cf. cinereus.

LOBATUS, a, um, adj. - Lobado. Ovário: com sulcos e saliências que se alternam segundo o comprimento. Lobatum est divisum ad medium in partes distantes, marginibus convexis (Lp): (a folha) lobada é dividida até o meio em partes afastadas, com margens convexas. Daí, bilobus, trilobus, etc. Folia lobata: folhas lobadas, quando os recortes (seios) não ultrapassam a metade da distância entre a margem e a nervura central 
(para outros, até quase a nervura central). As porções do limbo denominam-se lobos. Tais folhas podem ser designadas pelo número de lobos: tri-, bi-, etc., até multilobadas. Cf. palmatus, pinnatus, trilobus.

LOBUS, bi, subs. m. 2 - Lobo, parte de órgãos como folha e corola, p. ex. Antigo: pétala. A reliquis loborum elegantia (Lp): das restantes pela elegância das pétalas. Corollae forma loborum: pela forma dos lobos da corola. Cf. alte, basis, connivens, laciniatus, quoque, sinuatus.

LOCATUS, a, um, adj. - Colocado, localizado, posto. Semen paulo in latere locatum: a semente localizada um pouco de lado.

LOCELLATUS, a, um, adj. - Dividido em pequenas lojas.

LOCELLUS, $i$, subs. m. 2 - 0 mesmo que loculus. Locellis geminatim superpositis (FB): com os lóculos superpostos dois a dois.

LOCO, adv. - Lá, aqui; lugar. Também abl. sing. de locus. Eiusdem loco: do mesmo lugar.

LOCULAMENTUM, i, subs. n. 2 - Loja, lóculo, cavidade onde se alojam as sementes. Segundo Linné: loja da antera, do fruto, etc. Loculamentum, concameratio vacua pro seminum loco $(\mathrm{Lp})$ : loculamento, compartimento abobadado, oco, para abrigar as somentes. Unilocularis, etc. Cf. tandem.

LOCULARIS, e, adj. - Dotado de cavidades, lóculos ou lojas. Ovarium biloculare: ovário bilocular, com duas lojas.

LOCULICIDE, adv. - Que se abre segundo o lóculo. Capsulae loculicide dehiscentes (FB): cápsulas que se fendem ao longo da nervura central, no meio do lóculo.

LOCULICIDUS, a, um, adj. - Loculícido. Dehiscentia loculicida: processa-se ao longo da nervura central da folha carpelar; cada valva representa duas metades de dois carpelos contíguos. Própria dos frutos sincárpicos pluriloculares, junto com a deiscência septícida. Cf. septifragus.

LOCULUS, i, subs. m. 2 - Lóculo, loja, cavidade do fruto, ovário, antera, etc. Segundo Linné: loja da antera, do ovário. Loculi antherarum oblongi: as lojas das anteras oblongas. Cf. abortivus, ovulum, quisque.

LOCUPLES, locupletis, adj. - Rico, opulento; completo. Index locupletissimus (M): um índice o mais completo possível. Cf. servatus.

LOCUS, $\mathbf{i}$, subs. m. 2 - Lugar, local; posição. Locis asperis minimeque irriguis $(\mathrm{Pa})$ : em lugares acidentados, onde há muito pouca água. Cedrus saxosis locis gaudet $\mathrm{M}$ ): 0 cedro prefere (dá-se bem em) lugares pedregosos. Adjectis locis natalibus specierum (Lh): com inclusão dos locais de nascimento das (onde foram colhidas as) especies. Crescendi locus naturalis: o local natural onde cresce. Locus folii consideratur secundum punctum cui inseritur ipsi plantae (Lh): a posição da folha considera-se de acordo com o ponto em que se prende na própria planta. Cf. amo, apertus, asper, auctus, chasicus, continuo, depono, florista, glareosus, habitat, humorosus, invius, loculamentum, 
medicamentum, natalis, occurro, opacus, peculiaris, phyllodium, situs, solidus, stadium, studeo, sumo.

LOMENTACEUS, a, um, adj. - Semelhante ao, ou da natureza do, lomento. Lomentaceae (Lp): ordem de plantas, a maioria das quais fornece corantes e cujos frutos contêm sementes farináceas (como as do feijão). Quase todas são Leguminosas. Fructus lomentaceus: legume estrangulado de espaço em espaço, cada artículo contendo uma semente e se separando na maturidade. Folia lomentacea: folha composta cujo pecíolo é articulado de espaço a espaço (Citrus). Desusado.

LOMENTUM, i, subs. n. 2 - Lomento, cápsula articulada por septos transversais. Cf. lupinaceus.

LONDINIUM, i, subs. m. 2 - Londres. Cf. catalogus.

LONGE, adv. - Longamente, extensamente. Longe diversissima est planta $\mathrm{Lh}$ ): é planta muitíssimo diversa. Folia longe acuminata: folhas longamente acuminadas (= com acúmen comprido). Haud longe a mari (FB): perto do mar. Cf. aculeatus, caeterus, certus, ceu, conditio, distans, distat, excurro, late, ovato-lanceolatus, plerique, propello.

LONGIOR, oris, comp. de longus, a, um. N. e adv.: longius. Cf. bis, parumper, prior.

LONGITRORSUM, adv. - Em sentido longitudinal. Seminibus longitrorsum costatis (FB): com as sementes dotadas de cordões longitudinais em relevo ("costado"). Cf. sectus.

LONGITUDINALIS, e, adj. - Longitudinal. Cf. cuneiformis, ellipticus, oblongus, orbiculatus, striatus, subrotundus.

LONGITUDINALITER, adv. - Longitudinalmente. Cf. carinatus, exaro, obvallo, sectus, spatha.

LONGITUDO, udinis, subs. f. 3 - Comprimento. Staminibus et pistillis longitudine aequalibus (Lp): com os estames e pistilos iguais no comprimento. Cf. canaliculatus, dimidius, discurrens, ensiformis, linea, linearis, ludo, mediocris, pertransit, planus, quoad, spithama.

LONGUS, a, um, adj. - Longo, comprido. Pistillum staminibus longius (Lp): o pistilo mais comprido do que os estames. Folia $5 \mathrm{~cm}$ longa, petiolis $2 \mathrm{~mm}$ longis (FB): as folhas medem $5 \mathrm{~cm}$ no comprimento, com pecíolos de $2 \mathrm{~mm}$ de comprimento. $C$. aevum, appensus, comosus, computatus, jam, justo, longior, pariter, pinnatifidus, pone, quam, usque, vagina.

LOPHORHIZUS, a, um, adj. - Com raízes em cabeleira, penacho. Plantae lophorhizae (FB).

LORICA, ae, subs. f. 1 - Couraça; frústulo das Diatomáceas; séries de escamas nos frutos das palmeiras. Loricae squamis (FB). 
LORICATUS, a, um, adj. - Protegido por peças rígidas. Bacca squamis plurimis loricata (FB): a baga revestida por numerosas escamas duras.

LORUM (lorus), i, subs. n. 2 - Correia; açoite; rédeas. Cf. modus.

LOXINIS, e, adj. - Torto, encurvado, tortuoso. Plantae loxines (FB).

LUBRICANS, lubricantis, adj. - Que resvala, escorrega; que lubrifica. Segundo Lp.: lubricantia: plantas que lubrificam (mucilaginosas, etc.).

LUBRICUS, a, um, adj. - Liso, escorregadio; movediço; lúbrico. Lubrica saepius sunt (Lp): são, freqüentemente, inconstantes.

LUCIDUS, a, um, adj. - Brilhante, claro; luzidio, luminoso. Nitidum, quod glabritie lucidum est (Lp): (a folha) nítida é a que, sendo glabra, é brilhante. Cf. camera.

LUCROR, lucrando - Ganhar, lucrar; receber. Cf. panis.

LUDENS, ludentis, adj. - Que engana, joga, ilude; que varia. Indumentum colore ludens (FB): indumento que varia quanto à coloração.

LUDIBUNDUS, a, um, adj. - Que brinca, se diverte; que engana, varia. Planta valde ludibunda (FB): planta muito variável.

LUDICER, cra, crum, adj. - Relativo a jogo, divertimento, etc.; ilusório, enganoso. Pubescentia ludicra est differentia $(L p)$ : a pubescência é diferença ilusória.

LUDO, ludit, ludunt - Jogar, enganar, iludir; variar. Nectarium, si a petalis distinctum, communiter ludit (Lp): o nectário, ainda que distinto das pétalas, com freqüência engana. Hi duo flore facile ludunt tyrones (Lp): estas duas flores facilmente iludem o principiante. Folia inter orbiculare et lineare ludentia (FB): folhas que variam entre (as formas) orbicular e linear. Fructus colore fere ut flores lundunt (FB): os frutos variam, quanto à cor, quase como as flores. Praecipue foliorum forma ludit (FB): varia principalmente quanto à forma das folhas. Flores inter longitudinem $1 / 2$ lin. usque 1pedalem lundunt (FB): as flores variam entre o comprimento de meia linha até um pé. Ludit caeterum capsulis paucis (FB): varia, ademais, pelas cápsulas pouco numerosas. Cf. multifarie.

LUMBRICUS, i, subs. m. 2 - Verme intestinal, lombriga; minhoca. Cf. bis, fodio.

LUMEN, inis, subs. n. 3 - Luz, cavidade. Lumine cellularum angusto instructi: providos de luz celular estreita.

LUNULA, ae, subs. f. 1 - Dim. de luna, ae; luazinha, lúnula. Cf. linea.

LUNULATUS, a, um, adj. - Dim. de lunatus. Em forma de quarto lunar. Lunulatum est subrotundum basi excavatum, cum angulis posticis falcato-incurvis ( $\mathrm{Lh}$ ): (a folha) lunulada é arredondada, na base escavada, com os ângulos posteriores voltados para dentro. 
LUPINACEUS, a, um, adj. - De tremoço (Lupinus). Radices cum lomento lupinaceo $(\mathrm{Pa})$ : as raízes com lomentum (veja este) de tremoço.

LURIDUS, a, um, adj. - Lívido, pálido, amarelento.

LUSITANIA, ae, subs. f. 1 - Portugal. Cf. arvum.

LUSITANICE, adv. - Em português. Cf. dictus, stoma.

LUSITANICUS, a, um, adj. - Português, lusitânico; de Portugal. Cf. lingua.

LUTEUS, a, um, adj. - Lamacento; amarelo. Flores lutei. Cf. flores, inclinans, praeter, saturate, varius.

LUTOSUS, a, um, adj. - Lamacento. Crescit in locis lutosis: vive em lugares lamacentos.

LUTUM, i, subs. n. 2 - Espécie de lírio que cede corante amarelo (gauda); cor amarela. Folia trite cum luteo $(\mathrm{Pa})$ : esmague as folhas com gauda.

LUX, lucis, subs. f. 3 - Luz, claridade. Ad lucem prodiit (DC): veio à luz (saiu). Cf. erga, pervenio, prodeo.

LUXURIANS, luxuriantis, adj. - Luxuriante, exuberante, viçoso; flor dobrada. Luxurians flos tegmenta fructificationis ita multiplicat, ut essentiales ejusdem partes destruat (Lp): a flor luxuriante de tal modo aumenta os órgãos protetores (cálice e corola), que faz desaparecer as partes essenciais. Ab alimento luxuriante (Lp): devido à excessiva alimentação. Cf. orior.

LUXURIATIO, onis, subs. f. 3 - Viço, vigor. Cf. obnoxius.

LUXURIOR, luxuriat - Vicejar, crescer ou desenvolver-se luxuriantemente, luxuriar. Ubi luxuriat foliis majoribus (FB): onde viceja com folhas maiores.

LYMPHA, ae, subs. f. 1 - Água. Antigo: seiva. Lympha genitalis (Lp): a vulva.

LYRATUS, a, um, adj. - Lirado. Lyratum est transversim divisum in lacinias, ita ut superiores majores sint et inferiores remotiores (Lp): (a folha) lirada é dividida transversalmente em lacínias, de modo que as superiores sejam maiores e as inferiores mais afastadas. Lyratum est folium compositum, factum e simplici inferne diviso... (Lh): a folha lirada é composta, feita de uma simples inferiormente dividida ... É, de fato, folha simples, profundamente recortada e com o lobo terminal muito maior do que os laterais.

M - Abreviatura de metrum. Frutex $3 \mathrm{~m}$ altus: $\mathrm{o}$ arbusto com $3 \mathrm{~m}$ de altura.

MACER, macra, macrum, adj. - Magro, estéril (terra). In solo macro (Lp): em solo pobre. Collecta in arenoso et macerrimo solo: colhida em solo arenoso e paupérrimo. 
MACERATUS, a, um, adj. - Macerado; debilitado, enfraquecido. Herbam aqua maceratam cum aceto potu dabis $(\mathrm{Pa})$ : a erva, macerada na água, darás para beber com vinagre. Cf. fervens, materies.

MACILENTUS, a, um, adj. - Magro, pouco desenvolvido.

MACIS, dis, subs. f. 3 - Macis, arilo aromático da nóz moscada.

MACROPODINUS, a, um, adj. - O mesmo que macropodus. Há, ainda, macropodius. Embryo macropodinus (FB).

MACROPODUS, a, um, adj. - Macrópodo, com pé grande (pedúnculo, etc.). Embryo macropodus (FB): embrião dotado de radícula mais longa do que os cotilédones.

MACULA, ae, subs. f. 1 - Mácula, mancha. Corolla maculis tribus sericeis in medio tubi: a corola com três manchas seríceas no meio do tubo.

MADEFACTUS, a, um, adj. - Molhado, úmido. Cf. appropriatus, tumens.

MADENS, madentis, adj. - Que está umedecido, gotejado. Lacteoque suco madente (M): e umedecido por suco lateo.

MADIDUS, a, um, adj. - Como madefactus. Herbae suco madido linteolo nares obturet mox restringit $(\mathrm{Pa})$ : com um lenço umedecido no suco da erva o nariz fecha, depois aperta completamente. Cf. stigma.

MAEANDRUS (maeander), i, subs. m. 2 - Meandro. Maeandros Botanices errantes intrarent omnes (Lp): penetrassem em todos os perdidos meandros da Botânica.

MAECENAS, atis, subs. m. 3 - Mecenas, cidadão protetor dos poetas; por extensto: protetor das artes e ciências. Cf. botanion.

MAGIS, adv. - Comp. de magnopere. Mais. Magis magisque: cada vez mais. Magis ... quam: mais ... do que. Magis vel minus (Lp): mais ou menos. Genus hoc magis habitu quam characteribus scriptis definitum (FB): este gênero define-se mais pelo hábito do que por caracteres marcantes. Folia apicem versus magis magisque angustata: as folhas, na direção do ápice, cada vez mais estreitadas. Floribus magis glandulosis (FB): com flores mais glandulosas. Cf. anatomice, apte, convexus, definitus, depressus, pratum, ramosus, tendens.

MAGNAM PARTEM, expressão adverbial - Em grande parte. Cf. magnus, sponte.

MAGNITUDO, tudinis, subs. f. 3 - Tamanho, grandeza; grande quantidade. Semen sesamae magnitudine (M): a semente com o tamanho do (da de) sésamo. Magnitudine naturali $(\mathrm{Lp})$ : em tamanho natural. Planta integra naturali magnitudine (Lh): a planta inteira em tamanho natural. Cf. cerasum, crassities, distinguo, penis.

MAGNOLIUS, i, subs. m. 2 - Magnol, antigo botânico. Cf. combinatus.

MAGNOPERE, adv. - Muito, em alto grau; grandemente. Folia magnopere reticulata: as folhas muito reticuladas. 
MAGNUS, a, um, adj. - Grande, extenso. Magnam partem folia speciminis nostri insectis destructa sunt: as folhas do nosso exemplar foram destruídas, em grande parte, por insetos. Magnam partem Desmidiacearum: grande parte das Desmidiáceas. Cf. excresco, lexicon, momentum, pars, superior, tectus.

MAIOR (major), is, comp. m. e f. de magnus: maior. Folia maiora. Cf. analogia, dubium, earum, evado, ita, omnia, pro, scrutator.

MAIUS (majus), comp. n. de magnus - Maior. Stigma quam in illa maius: o estigma maior do que naquela. Também adv.

MAIUS (majus), a, um, adj. - De maio (mês).

MAIUS (majus), i, subs. m. 2 - Mês de maio. Cf. floreo.

MAJOR, majus - Veja maior, maius.

MALAGMA, ae, subs. f. 1 - Cataplasma. Radix pisata in malagma redacta ( $\mathrm{Pa})$ : a raiz moída e reduzida a cataplasma. Cf. commixtus, unguentum.

MALE, adv. - Mal. Cf. censeo, delineatus, vexatus.

MALPIGHIACEUS, a, um, adj. - Malpighiáceo, relativo às malpighiáceas; formado do nome de Marcello Malpighi, antigo pesquisador italiano. Pili malpighiacei (FB): pêlos bifurcados com longos ramos (lembram um compasso aberto). Pilis malpighiaceis inter se combinatis (FB): com pêlos malpighiáceos associados entre si (formando trama aplicada sobre a superfície).

MALUM, i, subs. n. 2 - Maçã. Cf. petiolus.

MALUS, la, lum, adj. - Ruim, mau; malvado, pérfido. Cf. collaticius.

MALUS, mali, subs. f. 2 - Macieira. Malus Persica: a figueira. Malus granata: a romanzeira. Mali granati sicci cortices: as cascas secas da romanzeira.

MAMMULA, ae, subs. f. 1 - Dim. de mamma: mamilo. Stamina primo quinque mammulas sepalis alterna praebentia: os estames apresentam, primeiro, cinco mamilos alternando com as sépalas.

MANCUS, a, um, adj. - Manco, defeituoso; imperfeito. Descriptio nimis manca; descrição muito mal feita, incompleta, etc. Specimen mancum (FB): exemplar defeituoso, imperfeito. Cf. etsi, putredo.

MANDUCATIO, onis, subs. f. 3 - 0 ato de comer. Sub manducatione semina (Lp): ao comer, as sementes.

MANDUCO, manducatur - Comer. Cf. balneus.

MANE, adv. - De manhã. Hodie mane: hoje pela manhã, esta manhã. Mane aperiuntur (Lp): abrem-se pela manhã. Cf. praesagio. 
MANIFESTE, adv. - Manifestadamente, claramente. Rami manifeste striati: ramos manifestadamente estriados.

MANIFESTO, adv. - 0 mesmo que manifeste. Cf. specto.

MANIFESTUS, a, um, adj. - Manifesto, evidente: bem desenvolvido. Bulbus minus manifestus occurrit in planta (Lh): o bulbo aparece na planta menos desenvolvido.

MANIPULUS, $i$, subs. m. 2 - Mão cheia ou punhado de algo; feixe, molho. Herbae manipulus in olla et aquae eminae tres: o feixe de erva, numa panela, e três heminae (medida) de água.

MANO, manat - Manar, correr; escorrer. Ex larice resina manat (M): a resina flui lentamente do Larix. Cf. truncus.

MANTISSA, ae, subs. f. 1 - Cógulo, o que ultrapassa a medida (o que sobra, p. ex., pela borda de um copo). Tomamos no sentido de suplemento ou complemento, isto é, o que apareceu depois da impressão de um trabalho. Mantissa ad Rubiaceas ou Rubiacearum: suplemento às Rubiáceas (no fim da monografia).

MANUDUCTIO, onis, subs. f. 3 - Manipulação. Manuductio ad materiam medicam (Lh): técnica de matéria médica.

MANUS, us, subs. f. 4 - Mão; braço. Mea manu satae sunt: foram plantadas por mim (pela minha mão).

MAPPA, ae, subs. f. 1 - Guardanapo; bandeirola. Mappa geographica: o mapa. Cf. monstro.

MARAGNANIENSIS, e, adj. - Maranhense. Provincia Maragnaniensis: o Maranhão.

MARCESCENS, marcescentis, adj. - Que seca antes de cair (cálice e corola). Pétalas: murcham sem cair.

MARCESCO, marcescit, marcescendo - Murchar(-se); debilitar-se. Quod illud marcescat (Lp): porque aquele murcha. Cf. brevi, persistens.

MARE, is, subs. n. 3 - Mar. Habitat in arenosis mari proximis (FB): vive em lugares arenosos junto ao mar. Cf. aestus, arenaria, circa, destruo, emergit, juxta, longe, Pacificus, praecedens.

MARGARITACEUS, a, um, adj. - Perolado, semelhante a pérola. Cf. nitens.

MARGARITIFER, a, um, adj. - Provido de pérola. Linné por ironia: com a superfície recoberta de vesículas.

MARGINALIS, e, adj. - Marginal; marcado ao longo das margens. Referente à margem ou bordo. Nervura: nervura formada, junto à margem, pela reunião das ramificações das nervuras secundárias ou laterais. Cf. nervus. 
MARGINATUS, a, um, adj. - Marginado. Folha: com os bordos espassados (sob lente). Semente: idem. Cf. facies.

MARGO, marginis, subs. m. ou f. (em Botânica m.) 3 - Margem. Margo est extrema ora folii ad latera (Lp): a margem é o limite extremo da folha nos lados. Limbus margine tenui calloso cinctus (FB): o limbo rodeado por margem tênue e calosa. Cf. acinaciformis, acquiro, adscendens, adglutinatus, albus, alter, anastomosans, basis, callosus, cartilagineus, ciliatus, crenatus, crispus, cum, dentatus, exeo, fatiscens, firmo, fissus, glandulosus, lacer, linearis, nigricans, petiolatus, quinquangularis, resus, tangens, triangularis, triens, trilobus, trivialis, undulatus, varie, via.

MARINUS, a, um, adj. - Marinho, marítimo. In locis marinis, saxosis (Pa): em lugares marítimos e pedregosos.

MARITIMUS, a, um, adj. - Marítimo, que vive junto ao mar; relativo ao mar. Maritima, orum, subs. pl. n. 2: locais costeiros, perto do mar. In maritimis nascens (M): que nasce (ou surge) em lugares junto ao mar. Cf. calidus, ora, paludosus, provenio, salsus.

MARMOR, marmoris, subs. n. 3 - Mármore. Marmoris albi colorem habet (M): apresenta a cor do mármore branco.

MARTINICENSIS, e, adj. - Da Martinica. Cf. amussis.

MARTIUS, i, subs. m. 2 - Março (mês); Martius, botânico alemão que criou a Flora Brasiliensis. Também adj.: relativo ao mês de março. Cf. Brasiliensis, floreo.

MAS, maris, subs. m. 3 - Homem; macho, animal; masculino, vegetal. Segundo Lp.: planta masculina, ou seja, só possuindo flores de tal sexo. In tilia mas et femima differunt omni modo (P): em tilia, a masculina e a feminina diferem em tudo. Marem adesse praedixi et reperi (Lp): afirmei que existe, e encontrei, a masculina (planta). Sepala eis maris similia: as sépalas são semelhantes às da (planta) masculina. Aspidium filix mas: Aspidium "feto macho". Cf. dum, foemina.

MASCULINUS, a, um, adj. - Masculino. Pouco usado em Botânica. Cf. genitalia, sperma.

MASCULUS, a, um, adj. - Masculino. Antigo: paleaceus, sterilis, abortiens. Flos mas culus (Lp): a que só leva estames. Para a planta usar-se-á mas. In masculo quidem folia apparent foliis bliti (M): na masculina, por certo, as folhas mostram-se como as de Blitum. Cf. absens, alabastrum, amentus, dabo, desidero, effetus, et, exemplar, firmstus, genus, perficio.

MASSA, ae, subs. f. 1 - Massa. Cf. agglutinatus, ejectus, foveo, mazaedium, odor, pollinicus.

MASTICO, mastices - Mascar, mastigar. Cf. ipse.

MATERIA, ae, subs. f. 1 - Material (para estudo, etc.); substância, matéria. Ad Medicae Materie studiosos (M): para os que estudam Matéria Médica. Ex materia in herbariis deposita (FB): consoante o material depositado nos herbários. Materia medica: patologia médica. Cf. ejus, impalpabilis, penuria, scatens. 
MATERIES, ei, subs. f. 5 - Em Botânica, sempre significa madeira ou material. Antigo: tronco. Materies resinosa (FB): matéria resinosa. Ligni materies durissima (M): madeira muito dura. Materies albida, in aquis macerata rubescens: a madeira é branca, tornando-se avermelhada quando macerada na água. Ad monographiam materiem amplam contulit (FB): reuniu grande material para a monografia. Cf. baculus, consto, ferulaceus, meditullium, medullitus, suppellex.

MATHEMATICE, adv. - Matematicamente; acuradamente. Cf. depingo.

MATRICALIS, e, adj. - Materno. Sporae in cellulis matricalibus mox delitescentibus oriundae (FB): esporos originados nas células-mães, as quais mais tarde desaparecem.

MATTHIOLUS, i, subs. m. 2 - Matthioli, botânico italiano da Renascença. Cf. commentarius, translatus.

MATURANS, maturantis, adj. - Que amadurece; que se desenvolve.

MATURESCO, maturescunt, maturescit - Amadurecer; desenvolver-se. Saepius maturescunt sterilia (Lp): com maior freqüência, amadurecem estéreis. Semina rarissime maturescunt (FB): as sementes mui raramente atingem a maturidade. $\mathrm{Cf}$. cito.

MATURITAS, atis, subs. f. 3 - Maturidade, madureza. Calyx maturitate fructus auctus: o cálice ampliado na maturidade do fruto. Cf. ampliatus, cadens, et, protrusus.

MATURUS, a, um, adj. - Maduro, completamente desenvolvido. Maturo fructu (Lp): estando maduro o fruto (= com a maturação do fruto; abl. abs.) Cf. anthera, carpellum, dimitto, dispergo.

MATUTINUS, a, um, adj. - De manhã, matutino, matinal. Cf. ros.

MAXIME, adv. - Superl. de magnopere: muitíssimo; sobretudo, principalmente. Legunt eam maxime cum flore $(\mathrm{Pa})$ : colham-na principalmente com flor. lis necessarium maxime opus (Lh): obra muitíssimo necessária aos. Maxime affinis: muitíssimo aparentado. In Brasilia maxime australi (FB): no Brasil, muitíssimo austral. Cf. accomodatus, affinis, amplio, anversus, fallax, usus.

MAXIMUS, a, um, adj. - Superl. de magnus: máximo, o mais entre todos. Maxima ex parte (Lp): na maior parte (quase todo). Radices maximam partem intra solum vivunt: as raízes, pela mor parte, vivem dentro da terra.

MAZAEDIUM, i, subs. n. 2 - Macédio, massa formada pelos esporos nos apotécios das Caliciáceas. Mazaedium sive massa sporalis nigricans: o macédio ou massa esporal negra.

$\mathrm{ME}$, acus. de ego - Me, para ou a mim. Cf. deficio, mitto, nolo, prius, visus.

MEATUS, us, subs. m. 4 - Movimento; passagem, canal. Meatus aerifer.

MEDIANUS, a, um, adj. - Mediano, colocado no meio. Bractea mediana: bráctea inserida no meio do pedúnculo. 
MEDIALIS, e, adj. - Mediano. Soris medialibus (FB).

MEDIANS, mediantis, adj. - Por meio de; mediante. Mediante copiosiore pulpa (Lp): por meio de polpa mais copiosa. Herbae mediantibus cirrhis scandentes (FB): ervas que trepam por meio de gavinhas. Cf. gibbus, illapsus.

MEDICAMEN, aminis, subs. n. 3 -- Medicamento, remédio. Cf. primus, simplex, spissus.

MEDICAMENTARIA, res ou ars, subs. f. 1 - A Farmácia ou ciência de preparar remédios. Cf. res.

MEDICAMENTUM, i, subs. n. 2 - 0 mesmo que medicamen. Medicamentum suprascriptum ( $\mathrm{Pa}$ ): o remédio (ou droga) acima mencionado. Medicamentorum facultates secundum locos (M): as propriedades dos remédios de acordo com o local (onde devem atuar). Cf. caute.

MEDICINA, ae, subs. f. 1 - Medicina; remédio. Cf. doctor, nullus, summus, usus.

MEDICINALIS, e, adj. - Medicinal, útil como remédio. Planta medicinalis: planta medicinal. Cf. effectus.

MEDICUS, a, um, adj. - Medicinal; de médico; da Média (região). Cf. empiricus (subs.), herba.

MEDICUS, $i$, subs. m. 2 - Médico. Medici quoque sine ea nihil curare possunt ( $\mathrm{Pa})$ : os médicos mesmo nada podem curar sem ela. Neronis Imperatoris Medicus (M): o médico do Imperador Nero. Recentiores medici (M): os médicos mais recentes. Cf. aestimo, materia, res, sectatus, studiosus.

MEDIETAS, atis, subs. f. 3 - Posição central, centro; metade. Supra medietatem (Lp): acima do meio.

MEDIMNUS (medimnum), i, subs. m. 2 - Medida para secos (52,5 litros). Valia 12 hemiecta segundo Dioscórides.

MEDIOCRIS, e, adj. - Medíocre, mediano; comum, vulgar. Thallus longitudine mediocris: o talo com comprimento médio.

MEDITERRANEUS, a, um, adj. - Do interior; da região do Mediterrâneo, etc. In regionibus mediterraneis (FB): nas regiões interiores. Habitat in prov. Bahiensis mediterraneis $(\mathrm{FB})$ : vive no interior da Bahia.

MEDITULLIUM, $\mathbf{i}$, subs. $\mathrm{n}$. 2 - Qualquer centro. Materies in caudicis meditullio sita (M): a madeira está colocada na porção mediana do tronco.

MEDIUM, i, subs. n. 2 - Meio, centro. Folia ex medio apicem versus: as folhas, do meio para o ápice. Tepala in medio $1 \mathrm{~cm}$ lata: as tépalas $\mathrm{com} 1 \mathrm{~cm}$ de largura no meio. Cf. calyptra, concavus, convexus, laciniatus, lanceolatus, macula, palmatus, quinquangularis, sextarius, subulatus, supra, teneo, trilobus. 
MEDIUS, a, um, adj. - Médio, intermediário; central, localizado no centro. In medio petiolo: no meio do pecíolo. Cf. costa, is, prominens.

MEDULLA, ae, subs. f. 1 - Medula, parte central. Caulis alba intus medulla (M): caule, interiormente, com medula branca. Medulla leni ac lento cremori simili (M): com medula semelhante a creme mole e brando. Cf. aquosus, arachnoideus, centralis, compono, crassus, digestus, factus, intricatus, pannus, separatus.

MEDULLARIS, e, adj. - Medular, da medula, do centro. Radius medullaris: raio medular. Canalis medullaris: cavidade cilindrica, no centro do caule, cheia de medula. Cf. crystallus, processus, radius, reagens.

MEDULLITUS, adv. - Que atinge o fundo. Materies medullitus vero nigra (M): a madeira, realmente, é negra até o fundo (cerne).

MEDUSA, ae, subs. f. 1 - Medusa, entidade mitológica possuidora de cabelos dourados, com os quais seduziu Netuno. Cf. caput.

MEL, mellis, subs. n. 3 - Mel; doçura. Cf. eodem, per, pidabo, plerunque, uncia.

MELANCHOLICUS, a, um, adj. - Pendente, voltado para baixo. Segundo Lp., como metáfora: planta cujas flores cheiram só à noite.

MELIOR, comp. m. e f. de bonus - Melhor. Cf. frustra.

MELIUS, adv. - Comp. de bene: melhormente, mais. Ainda comp. $n$. de bonus: melhor. Cf. propago (subs.).

MELLEUS, a, um, adj. - De cor amarela como o mel. Cf. secerno.

MELLIFER, a, um, adj. - Que faz provisão de mel (abelhas); melífero. Cf. nectarium.

MELO, onis, subs. f. 3 - Melão. Meloformis, e, adj.: em forma de melão. Cf. aufero.

MEMBRA, orum, subs. pl. n. 2 - Membros ou partes de um conjunto. Cf. systema.

MEMBRANA, ae, subs. f. 1 - Membrana, parede celular; película. Cf. ala, carnosus, conferruminatus, incrassatus, obvolutus, promissus.

MEMBRANACEUS, a, um, adj. - Membranáceo, tendo a consistência das membranas, isto é, mais ou menos translúcido. Membranaceus quod intra utranque superficiem evidenti nulla pulpa scatet (Lp): (a folha) membranácea, entre as duas superfícies, não tem polpa evidente. São folhas finas, mais ou menos translúcidas contra a luz. Cf. ala, cartilagineus, trigonus, volva.

MEMBRUM - Veja membra.

MEMORATUS, a, um, adj. - Mencionado, contado. Fruticum supra memoratorum species (Lh): as espécies de arbustos acima mencionados. Cf. hic. 
MEMORIA, ae, subs. f. 1 - Memória; lembrança. In memoriam revocat (revocans) (FB): traz (que traz) à memória. Cf. addisco, adeoque, consecro, dictus, mens.

MENS, mentis, subs. f. 3 - Mente; caráter; lembrança, idéia. Dubia mente: dubiamente, duvidosamente. Seminibus Farameas in mentem revocat (FB): pelas sementes traz à lembrança as espécies de Faramea.

MENSIS, mensis, subs. m. 3 - Mês. Singulis mensibus: todos os meses. Lege eam mense augusto $(\mathrm{Pa})$ : colha-a em agosto. Germinare mense septembri incipit $(\mathrm{M})$ : começa a germinar no mês de setembro. Cf. florens.

MENSURA, ae, subs. f. 1 - Medida, medição, mensuração. Tournefort introduziu a prática de medir os órgãos vegetais ao descrevê-los. Linné, porém, restringiu-a aos casos em que há comparação. Mensura cyathi unius $(\mathrm{Pa})$ : na medida de um ciato. Cf. aridum, metricus, ratio, typus.

MENTIENS, mentientis, adj. - Que simula, aparenta enganosamente. Muscorum habitum mentientes (FB): que simulam o aspecto dos musgos.

MENTIO, onis, subs. f. 3 - Menção. Cf. ut.

MERDA, ae, subs. f. 1 - Excremento. Arbor merdam olens (Lh): árvore que rescende a excremento.

MERE, adv. - Puramente. Cf. axylinus, immo.

MERIDIES, ei, subs. m. 5 - Meio dia; sul (na Europa). Cf. adversus, sinistrorsum.

MERIDIONALIS, e, adj. - Meridional, austral, do sul, sulino. Cf. adporto.

MERITO, adv. - Merecidamente, com razão. Ut merito Calceolaria appellari possit (M): que, com razão, pode ser chamada Calceolaria.

MERITUS, a, um, adj. - Merecido, justo. De Palmis Brasiliensibus optime meritus (FB): que muito bem mereceu (pelos seus trabalhos) acerca das palmeiras brasileiras.

MERUM, i, subs. n. 2 - Vinho puro, não misturado com outras substâncias. Herba pisata cum mero potui data $(\mathrm{Pa})$ : a erva esmagada, dada a beber com vinho puro.

MERUS, a, um, adj. - Puro, não misturado; legítimo; mero. Cf. varietas.

MESIDIUM, i, subs. n. 2 - Mesídio. Labello hypochiliato vel mesidiis pleuridiisque instructo (FB): com o labelo hipoquiliado ou dotado de mesídio e pleurídio.

MESOCARPIUM, i, subs. n. 2 - Mesocarpo. Cf. dissolvens, mirus.

MESOPHYLLUM, i, subs. n. 2 - Mesofilo, conteúdo verde da folha entre as duas epidermes. Bracteae mesophylla desunt (FB): as brácteas não possuem mesofilo. Cf. oleifer.

METALLICE, adv. - Metalicamente. Cf. splendens. 
METALLICUS, a, um, adj. - Metálico, refere-se geralmente ao brilho ou aspecto da superfície. Baccae nitore metallico subaureo donatae (FB): as bagas dotadas de brilho metálico quase dourado.

METAMORPHOSIS, is, subs. f. 3 - Metamorfose; transformação. Metamorphosis insectorum surinamensium: metamorfose dos insetos de Surinam. Metamorphosis Saponariae anglicanae (Lp): a metamorfose da Saponaria inglesa.

METEORICUS, a, um, adj. - Referente à atmosfera, meteórico. Meteorici flores solares (Lp): as que se abrem e fecham em determinadas horas do dia por razões atmosféricas (sombra, umidade, secura, pressão, etc.).

METHODICUS, i, subs. m. 2 - Metodista, no sentido de botânico sistemata. Methodici de dispositione et inde facta denominatione vegetabilium imprimis laborarunt (Lp): os metodistas trabalharam principalmente sobre a ordenação, e a decorrente nomenclatura, dos vegetais. Cf. Botanice.

METHODUS, i, subs. f. 2 - Método. Ex methodo apud Botanicos recepta (Lh): de acordo com o método admitido entre os botânicos. Genuina methodo (Lp): pelo verdadeiro método. Methodus sexualis: o sistema de Linné. Methodus Calycina (Lh): método baseado nos caracteres do cálice. $\mathrm{Cf}$. alphabetarius, audio, conscriptus, disponendus, fragmentum, orthodoxus.

METIENS, metientis, adj. - Que mede. Squamis in diametro $3 \mathrm{~mm}$ metientibus (FB): escamas que medem $3 \mathrm{~mm}$ de diâmetro. Cf. solitum.

METRALIS, e, adj. - Que tem um metro. Caulis metralis. Arbor quinquemetralis: árvore com 5 metros.

METRICUS, a, um, adj. - Métrico, referente ao metro. Mensurae unice metricae adhibeantur: que sejam empregadas unicamente as medidas métricas (do sistema métrico).

METROPOLIS, is, subs. f. 3 - Metrópole. In Rio de Janeiro prope metropolin imperii (FB): no Rio de Janeiro, nas proximidades da metrópole imperial.

METRUM, i, subs. n. 2 - Metro, medida de extensão. Frutex 3 metris altus: arbusto com 3 metros de altura. Usa-se, todavia, somente abrev.: m. Cf. m.s.m.

MEUS, mea, meum, adj. - Meu. Erroris causa mei: em razão de um erro meu. In speciminibus meis (FB): nos meus exemplares. Cf. colo, manus, similis.

MICACEUS, a, um, adj. - Micáceo. Cf. schistos.

MICRA, indecl. - Micra, plural de micron, 1 milésimo de milímetro $(0,001 \mathrm{~mm})$. Representa-se pela letra grega $\mu$. Pollinis granula circiter 30 micra diam.: os grãos de pólen com cerca de $30 \mu$ no diâmetro. Cf. crassus, diam. Em vernáculo, micro e micros.

MICROPHYLLINUS, a, um, adj. - Com pequenas folhas. Ramulis dense microphyllinis (FB): com os râmulos densamente cobertos de pequenas folhas. 
MICROPYLE (micropyla), es, subs. f. 1 - Micrópila ou micrópilo, pequeno orifício no óvulo - às vezes visível na semente - por onde penetra o tubo polínico para operar a fecundação. Radice ad micropylen spectante (FB): com a raiz dirigida para a micrópila.

MICRORETICULATUS, a, um, adj. - Microrreticulado. Cf. igitur.

MICROSCOPIUM, i, subs. n. 2 - Microscópio. Cellulae inde a 500 x sub microscopio detergibiles: as células perceptíveis ao microscópio desde 500 aumentos. Cf. inquiro, visus.

MIHI, adv. - Para mim, por mim. Itaque mihi haud visae: e assim não vistas por mim (plantas). Species mihi valde dubia (FB): a espécie, para mim, é muito duvidosa. Cf. appictus, genus, hactenus, missus, nomen, quid, video.

MILIARIS, e, adj. - Miliar, que lembra o grão de milho; por extensão: de pequenas dimensões. Scabrities glandulosa miliaris (Lp): aspereza devida a diminutas glândulas.

MILITO, militare - Prestar serviço, trabalhar em; pertencer, etc. Sub eodem genere militare non posse $(\mathrm{Lp})$ : não teriam podido permanecer no mesmo gênero.

MILLE, numeral indecl. sing. - Mil; muitíssimo. O pl. milia, ium é decl.: milhares. Millefoliatus, millefolium: com mil folhas, isto é, um número muito grande. Cf. auctus.

MILLIMETRALIS, e, adj. - Com 1 milímetro. Antherae vix millimetrales: as anteras com apenas $1 \mathrm{~mm}$ no comprimento. Cf. ultra.

MILLIMETRUM, i, subs. n. 2 - Milímetro. Usa-se abrev.: mm. Cf. solitum.

MINA, ae, subs. f. 1 - Medida de peso (324 g). Dioscórides (M) cita três espécies: $\mathrm{m}$. Medicorum (16 onças), m. Italica (18 onças) e m. Alexandrina (20 onças).

MINAE GENERALES, arum, ium, expressão subs. - Minas Gerais. Minarum Generalium Provincia: o Estado de Minas Gerais. Minarum: de Minas Gerais. Cf. campus, civ.

MINERALIS, e, adj. - Mineral. Cf. dissimilis.

MINIATUS, a, um, adj. - Da cor do cinábrio; vermelho. Cf. apex, inclinans.

MINIME, adv. - Superl. de non multum: mínimo, o menor; muito pouco. Foliis minime spinosis (M): com as folhas muito pouco espinhosas. Nobis autem minime (Lp): para nós, todavia, de nenhum modo. Formae minime rarae (FB): formas muito raras. Cf. locus.

MINIMUS, a, um, adj. - Superl. de parvus: mínimo, o menor de todos. Cf. crassitudo, moles, papillosus, particula, tuber.

MINISTRO, ministrare - Servir à mesa. Alimentum ministrare videtur (Lp): parece fornecer o alimento.

MINOR, comp. m. e f. de parvus: menor. Profert calycem corolla minorem (Lp): apre- 
senta o cálice menor do que a corola. Cf. ac, caeterus, crassitudo, ceu, duplo, gradus, individuum, omnia, specto, usus.

MINUS, comp. n. de parvus - Menor. Ainda adv. minus: o menos (comp. de non multum). Plus minusve: mais ou menos. Longe minus: muito menos (adv.). Fructus minus odoratus quam flores: fruto menos perfumado do que as flores. Flores minus brevis foliis: as flores são menos curtas do que as folhas. Minus insignis flore (Lp): menos evidente do que a flor. Cf. aculeatus, botanicus, contineo, deltoides, epitheton, hiscens, huic, magis, manifestus, obnoxius, plus, soleo, ve, verbum.

MINUSVE - Minus com a enclítica ve: ou menos. Da locução plus minusve ou plus vel minus: mais ou menos. Cf. induvia.

MINUTIES (minutia, ae), es, subs. f. 5 - Pequenez, pequeneza. Saltem minutie caryopseos (FB): pelo menos em razão do pequeno tamanho das cariópses.

MINUTUS, a, um, adj. - Diminuído; pequeno, minúsculo. Cf. adeo, exorior, insculptus, proximus, quae, redactus, refertus.

MIRABILIS, e, adj. - Admirável; singular; extraordinário. Exemplo mirabili (Lp): como exemplo admirável. Cf. utilis.

MIRE, adv. - Admiravelmente, grandemente, extremamente. Cf. dolor, tumor.

MIRIFICE, adv. - $\mathrm{O}$ mesmo que mire. Mirifice morsum sanat $(\mathrm{Pa})$ : cura admiravelmente a mordida.

MIRUS, a, um, adj. - Extraordinário, singular, admirável, notável. Mirum in modum, miro modo: de um modo admirável, extraordinariamente; muitíssimo. Mira est Cupressi foecunditas (M): é admirável a fecundidade do çipreste. Ut miro modo (Lp): de maneira admirável. Mesocarpio mirum in modum incrassato (FB): com o mesocarpo muitíssimo engrossado. Cf. consilium, modus.

MISCEO, misce - Misturar; unir, ligar. Cf. piper.

MISSIO, onis, subs. f. 3 - Envio; missão. Prope missionem S. Jago (FB): perto da missão de S. Jago.

MISSUS (de mitto), a, um, adj. - Enviado, mandado. Sibi missum ex (M): enviado a ele de (tal lugar). Plantae mihi missae: as plantas mandadas para mim. Cf. cardo.

MITIGATUS, a, um, adj. - Amolecido, suavizado; amadurecido; amansado; acalmado. Cf. comedo.

MITIS, e, adj. - Tenro, macio, suave. (Arbores) ex acerbo fructu mitem porrigunt (Lp): (árvores) de um fruto desagradável ao paladar dão um fruto suave. Cf. oleum, scatens.

MITTO, mittatur, mittit, misit, mittunt - Entre outras acepções: produzir, emitir, gerar, apresentar; mandar, enviar; rejeitar, demitir. Caulium bases radices plurimas mittunt: as bases caulinares produzem numerosas raízes. Flores parvos, muscosos mittit 
(M): apresenta flores pequenas, com aspecto de musgo. Quae ad me misit (M): que enviou a mim. Mitto genera non definita (Lp): rejeito os gêneros não definidos. Ex Brasilia semina Berolinum misit (FB): mandou sementes do Brasil para Berlim. Cf. appictus, flos, laudabilis, thyrsus.

MIXTUS, a, um, adj. - Mixto; misturado. Herbae sucum mixtum cum croco bibat $(\mathrm{Pa})$ : beba o suco da erva misturado com açafrão.

MOBILIS, e, adj. - Móvel, movediço. Antherae mobiles: anteras móveis (versáteis). Cf. necessarius.

MODERATE, adv. - Moderadamente, prudentemente. Cf. explicandus.

MODESTUS, a, um, adj. - Ponderado, circunspecto, refletido; cauteloso; disciplinado.

MODICE, adv. - Moderadamente. Petala modice unguiculata: as pétalas moderadamente unguiculadas (com as unhas medíocres). Folia modice cuneata, etc. Cf. prelum.

MODICUS, a, um adj. - Medíocre, mediano, moderado. Cf. sectus.

MODIUS, i, subs. m. 2 - Módio, medida para secos (8,754 litros). 0 m. Aegyptius e o m. Italicus valem oito chenicas (Dioscórides). Cf. artaba.

MODO, adv. e conj. - Agora mesmo; só; contanto que. Modo ... modo . . . : ora .. . ora ... Inflorescentiae modo corymbosae modo racemosae: as inflorescências às vezes corimbosa, às vezes racemosa. Simplex est, cum petiolus unicum modo gerit folium (Lh): (a folha) é simples quando o pecíolo exibe somente uma folha. Cf. conjugatus, sulcatus.

MODUS, i, subs. m. 2 - Modo, maneira; termo. Solito modo: geralmente, habitualmente. Multis modis: de muitas maneiras, por muitos modos. Hoc modo: deste modo, desta maneira. Mirum in modum: de modo espantoso; muito. Ad modum: à maneira de. Lori modo flexilis (M): flexível como (à maneira de) correia. Rami in rotae modum caudicem cingunt (M): os ramos circundam o tronco como roda (verticilados). Modo, quo flores gerit (Lp): a maneira pela qual as flores surgem. Modi florum aggregatorum septem primarii sunt (Lp): são sete os tipos principais de flores agregadas. Modo singulari (Lp): de maneira singular. Triplici modo Lp): de três maneiras. Cf. adhaerens, constructus, dictus, edo, fio, inflorescentia, insertio, intortus, mirus, nullus, racematim, radians, similis, solitum.

MOLES, is, subs. m. 3 - Grande volume; colosso; força; esforço; dificuldade. Sub minima mole (Lp): com pequeno esforço. Semina cerasi mole (FB): as sementes com o volume duma cereja. Cf. augeo.

MOLLIS, mollis, molle, adj. - Macio, frouxo, tenro; dotado de pêlos macios. Mendoncia mollis: cujos pêlos são macios. Cf. dehisco, enodis, gustatus, productus, tactus, villosus.

MOLLISSIME, adv. - De modo extremamente mole, tenro. Cf. tunsus. 
MOLLITER, adv. - Molemente, maciamente; delicadamente. Floribus molliter pubescentibus: com as flores maciamente pubescentes. Cf. undique.

MOMENTUM, i, subs. n. 2 - Esforço; importância; decisão; período, momento. Magni momenti res (Lp): coisa de grande importância. Notae minoris momenti (FB): dados de menor importância. Usus parvi momenti est (FB): o uso é pouca importância. Aliisque momentis levioribus (FB): e por outros (caracteres) de menor importância, de peso mais leve. Cf. nota.

MONACENSIS, e, adj. - De Mônaco. In horto bot. Monacensi (FB): no Jardim Botânico de Mônaco.

MONEO, monuit - Lembrar; aconselhar; anunciar, predizer. Martius potissime Eriocaulaceas a Restiaceis differre optime monuit (FB): Martius sobretudo esclareceu perfeitamente que as Eriocauláceas diferem das Restiáceas.

MONOCARPEUS, a, um, adj. - Monocárpico, que frutifica somente uma vez e desaparece em seguida.

MONOCARPICUS, a, um, adj. - O mesmo que monocarpeus. Plantae monocarpicae (FB).

MONOCHLAMYDEUS, a, um, adj. - Monoclamídeo, grupo de plantas dotadas só do cálice (sem corola).

MONOCLINIS, e, adj. - Andrógino (FB).

MONOCLINUS, a, um, adj. - 0 mesmo que monoclinis. Spadix monoclinus (FB).

MONOGRAPHIA, ae, subs. f. 1 - Monografia. Monographia Moracearum:monografia das moráceas. Monographia Martiana (ou Martii): monografia de Martius. Cf. materies, Phanerogamus.

MONOGRAPHUS, i, subs. m. 2 - Monógrafo. Monographi vegetabile unicum, opere singulari, prosecuti sunt $(\mathrm{Lp})$ : os monógrafos descreveram uma única planta numa só obra.

MONOICUS, a, um, adj. - Monóico. Monoica in eodem spadice: espécie (planta) monóica no mesmo espádice (o espádice com flores femininas e masculinas). Cf. casus.

MONOPETALOIDES, is, adj. - Cf. multifidus. Desusado.

MONOPETALUS, a, um, adj. - Monopétalo, com uma pétala. Usado, sempre, impropriamente, para designar corola com as pétalas soldadas (que é: gamopétala). Corolla monopetala (Lp): para Linné havia, realmente, só uma pétala neste tipo e, pois, o nome era correto. Hoje, não o é mais, sob outro conceito. Cf. multiplico, oides, refero, simul, statuo.

MONOPHYLLUS, a, um, adj. - Monofilo. Linné: cálice gamossépalo. Involucrum monophyllum (Lp): invólucro inteiro. Spatha monophylla (Lp): espata íntegra. Cf. quo- 
MONOSPERMUS, a, um, adj. - Linné: com um óvulo (ovário) ou semente (fruto).

MONOSYMMETRICUS, a, um, adj. - Com um plano de simetria apenas. Zigomorfo. Flores monosymmetrici (FB).

MONOTYPICUS, a, um, adj. - Monotípico. Genus monotypicum (FB): com uma única espécie.

MONS, tis, subs. m. 3 - Monte, serra, montanha. Montis radix: raiz ou pé do monte. Nascitur in montium radicibus locis solidis: ocorre em lugares firmes na raiz das serras. In montibus locis humidis: nos montes, em locais úmidos. Montes Organenses: Serra dos Orgãos. In montibus Tijuca: no morro da Tijuca. Cf. alpestris, colligo, e, scaturigo, summus, udus.

MONSTRO, monstrat, monstrant - Mostrar, revelar. Plantae omnes utrinque affinitatem monstrant, uti territorium in mappa geographica $(\mathrm{Lh})$.

MONSTROSITAS, atis, subs. 3 - Mònstruosidade. Cf. gradus.

MONSTROSUS (monstruosus), a, um, adj. - Monstruoso, teratológico, deformado, anormal. Cf. significans.

MONSTRUM, i, subs. n. 2 - Qualquer fenômeno extraordinário; monstro. Folia omnia crispa monstra sunt $(\mathrm{Lp})$ : todas as folhas crespas são anormais (= não produzidas em condições naturais).

MONTANUS, a, um, adj. - Montanhês, vivendo em lugares altos. In silva montana ad: na mata serrana em.

MONTOSUS, a, um, adj. -0 mesmo que montuosus. Habitat in montosis prope (FB): vive nos lugares montanhosos perto de. Cf. consitus.

MONTUOSUS, a, um, adj. - Montuoso, montanhoso. Cf. cultus.

MONUMENTUM, i, subs. n. 2 - Lembrança; monumento; documentos. Cf. consecro, tectum.

MORA, ae, subs. f. 1 - Demora; pausa; duração, obstáculo. Sine mora sanabitur (Pa): cura-se sem demora, prontamente.

MORBOSUS, a, um, adj. - Doente. Plantae morbosae (Lp): plantas doentes.

MORBUS, i, subs. m。 2 - Doença. Linné: doença das plantas. Pelletur morbus (Pa): cura-se a doença (elimina-se). Morbi ergo morbis curantur (Lp): as moléstias, por conseguinte, são curadas pelas moléstias. Cf. prout, utor.

MORDAX, acis, adj. - Que morde; cortante; acre, amargo; picante. Segundo Lp., como metáfora: planta de sabor acre.

MORE, adv. - À maneira de, como. Labellum more folii fimbriatum (FB): o labelo 
fimbriado como a folha. Vagina more generis fissa (FB): a bainha é fendida como no (no resto do) gênero. Cf. reliquus.

MORIOR, mori - Morrer; perecer; findar. Cf. oppositus.

MOROSUS, a, um, adj. - Exigente, impertinente; teimoso; lento. Cf. natu.

MORPHOLOGIA, ae, subs. f. 1 - Morfologia. Cf. adversaria.

MORPHOLOGICE, adv. - Morfologicamente. Quomodo caules morphologice evolvantur (FB): o modo pelo qual os caules desenvolvem-se morfologicamente.

MORPHOLOGICUS, a, um, adj. - Morfológico, relativo ao estudo das formas e estruturas. Natura morphologica haustrorum ambigua est (FB): a natureza morfológica dos haustórios é incerta.

MORPHOSIS, is (eos), subs. f. 3 - Fenômeno que leva à produção ou modificação de uma forma ou estrutura. Modo de desenvolvimento; ordem segundo a qual os órgãos se completam, do início ao fim. De lycopodinearum morphosi (FB): sobre o processo de desenvolvimento das licopodíneas.

MORS, mortis, subs. f. 3 - Morte. Cf. eripio.

MORSUS, morsus, subs. m. 4 - Mordedura, dentada. Ad canis rabiosi morsum ( $\mathrm{Pa}$ ): para (curar) mordida de caẽs raivosos. Cf. mirifice.

MORTARIUM, i, subs. n. 2 - Gral. Destringis folia in mortario (Pa): machucas as folhas num almofariz.

MORTIFER (mortiferus), a, um, adj. - Mortífero. Folia jumentis mortifera (M): as folhas são fatais para os animais de carga.

MORTUUS, a, um, adj. - Morto. Segundo Lp., como metáfora: espécie inerme.

MORUM, i, subs. n. 2 - Amora. Herbae rubi aut flos aut mora (Pa): ou a flor ou as bagas da erva Rubus (framboesa).

MORUS, mori, subs. f. 2 - Amoreira. Herbae mori folia recentia trita (Pa): as folhas frescas da amoreira trituradas. Moris forma similis (M): semelhante às amoreiras pela forma.

MOS, moris, subs. m. 3 - Vontade; costume, uso. Contra morem Diplazii (FB): ao contrário do que sucede em Diplazium. De Podostemacearum moribus (FB): sobre os hábitos das Podostemáceas.

MOTUS, us, subs. m. 4 - Movimento; andamento, curso. Contra motum solis (Lp): em sentido contrário ao movimento do Sol. Motus voluntarius (Lp): movimento voluntário. Cf. constitutus, defectus.

MOX, adv. - Logo, daqui a pouco, em seguida; depois; mais tarde. Capsula velutina, mox glabra: a cápsula é velutina, depois glabra. Genus mox determinabit (Lp): logo de- 
terminará o gênero. Ex his arboribus stillat balsamum limpidum, mox congelascens (Ma): destas árvores goteja um bálsamo claro, que depois endurece. Cf. brevi, dens, madidus, matricalis, primo.

M.S.M. -Abrev. de metra super mare: metros sobre o mar; 550 m.s.m.

MUCIGER, a, um, adj. - Que produz muco. Cellulis epidermidis mucigeris (FB): células da epiderme que produzem muco ou mucilagem. Cf. epidermis.

MUCILAGo, inis, subs. f. 3 -Mucilagem. Cellulis mucilagine lutea repletis (FB): com células cheias de mucilagem amarela.

MUCRO, nis, subs. m. 3 - Mucro, mucrão, ponta aguda. Linné: ejaculadores das Acanthaceae. DC: apículo rígido e retilíneo. Folia in mucronem desinentia (M): as folhas terminando em ponta, mucrão. Folia apice in mucronem porrecta: as folhas prolongadas, no ápice, em mucro. Cf. aculeus, arista, instructus, spina.

MUCRONATUS, a, um, adj. - Mucronado, que termina em mucro ou ponta aguda. Antigo: agudo, pontudo. Folia ex lata origine mucronata (M): as folhas agudas com base larga. Cf. conspicue, distincte.

MULSUS, a, um, adj. - Preparado com mel. Herbae radix ex aqua mulsa ( $\mathrm{Pa}$ ): a raiz da erva com hidromel (água e mel). Cf. drachma.

MULTIFARIAM, adv. - Em muitos pontos, direçð̃es, séries, modos. Cf. quadrifariam, trifariam.

MULTIFARIE, adv. - De muitas maneiras ou modos. Facies specierum multifarie ludit (FB): varia de muitas maneiras pelo hábito das espécies.

MULTIFARIUS, a, um, adj. - Disposto em muitas séries; de várias maneiras. Folia tri-multifaria (FB): folhas dispostas em 3 a muitas séries em torno do ramo.

MULTIFIDUS, a, um, adj. - Muitas vezes fendido, multífido. Antigo: laciniatus, monopetaloides. Linné: corola "monopétala", dividida em vários segmentos. Cf. bifidus.

MULTILINGUIS, e, adj. - Multilíngue. Index multilinguis: índice (glossário) multilíngue ou poliglota. Cf. index, lexicon.

MULTIPARTITUS, a, um, adj. - Muitas vezes partido. Cf. partitus, quinquepartitus.

MULTIPLEX, icis, adj. - Numeroso; vasto, grande; múltiplo. Multiplex ordo petalorum (Lp): uma série muito grande de pétalas: Spica multiplici sparsa: com a espiga vasta e espalhada. Cf. fructus.

MULTIPLICATIO, onis, subs. f. 3 - Aumento, acréscimo, multiplicação. Cf. generatio.

MULTIPLICATUS, a, um, adj. - Multiplicado; aumentado. Linné: flor com corola dupla, tripla ou quádrupla. Não há eliminação de todos os estames, sempre restando alguns. Cf. caveo, distinguo, idea, potius, praedico. 
MULTIPLICO, multiplicat - Multiplicar; aumentar. Monopetali saepius multiplicantur (Lp): os monopétalos freqüentemente são multiplicados. Cf. luxurians.

MULTO, adv. - Muito. Cf. altior.

MULTOTIES, adv. - Muitas vezes. Hilo quam caryopsis muitoties breviore (FB): com o hilo muitas vezes mais curto do que a cariópse. Cf. supradecompositus.

MULTUM, adv. - Muito. Non multum: não muito.

MULTUS, a, um, adj. - Muito, freqüente, numeroso, abundante. Paucis multa:(dizer) muitas coisas em poucas (palavras). Facit ad remedia multa $(\mathrm{Pa})$ : convém para muitos remédios. Cf. annus, consimilis, exsupero, flosculus, gaudeo, gravidus, horrens, iste, modus, nomen, pauci.

MULUS, i, subs. m. 2- Burro. Mulus ex equa et asino (Lp): o burro, oriundo da égua e do jumento. Cf. utor.

MUNDUS, a, um, adj. - Limpo; elegante. Cf. opacus, pratensis.

MUNDUS, i, subs. m. 2 - Mundo, Terra. Cf. cardo.

MUNITUS, a, um, adj. - Defendido, fortificado; dotado de; guarnecido de grandes brácteas; protegido por (segue abl.); protegido contra (prep. ab ou contra). Pileus corona pilotum munitus: o píleo protegido por coroa de pêlos. Antherae ab avibus petalis munitae: as anteras protegidas contra as aves pelas pétalas. Nectaria contra insecta tubo corollino munita: os nectários protegidos contra os insetos pelo tubo da corola. Flores basi bractea muniti (FB): as flores dotadas de uma bráctea na base.

MURICATULUS, a, um, adj. - Dim. de muricatus. Cf. etiam.

MURICATUS, a, um, adj. - Provido de pontas grossas, conspícuas; muricado, tornado áspero por meio de pontas duras. Cf. detritus, echinatus.

MURUS, i, subs. m. 2 - Muro, muralha. Cf. saxum.

MUS, muris, subs. m. 3 - Rato, particularmente o camundongo. Cf. eneco.

MUSAEUM, i, subs. n. 2 - Museu. Musaeum Musaeorum: o museu dos museus.

MUSCA, ae, subs. f. 1 - Mosca. Cf. capto.

MUSCOSUS, a, um, adj. - Coberto de musgos. Cf. lapis, mitto.

MUSCULARIS, e, adj. - Muscular. Cf. fibra.

MUSCUS, i, subs. m. 2 - Musgo. Musci frondosi: musgo com "folhas" (frondes). Cf. absolvo, adeo, adhaerens, agmen, calyptra, elaboro, familia, ferax, propago, pulvinus, scatens, terminus.

MUSEOGRAPHUS, phi, subs. m. 2 - Descritores de museus. Por ex., a obra de Grew 
"Musaeum Regalis Societatis" (o Museu da Sociedade Real).

MUSEUM, i, subs. n. 2 - Museu. Cf. asservatus, custos.

MUTABILIS, e, adj. - Mudável, variável; inconstante. Cf. an.

MUTATUS, a, um, adj. - Mudável; mudado, trocado. Squamae in folia parva mutatae (FB): ascamas transformadas em folhas pequenas. Cf. species.

MUTICUS, a, um, adj. - Obtuso, sem pontas; desarmado. Antherae muticae (FB): anteras obtusas, sem quaisquer apêndices. Cf. theca.

MUTILATUS, a, um, adj. - Mutilado. Stamen mutilatum (Lp): estaminódio.

MUTILUS, a, um, adj. - Mutilado. Linné: flor anormal em que a corola está ausente, quando deveria existir.

MUTUATUS, a, um, adj. - Emprestado. Icones ex aliis mutuatae (Lh): desenhos tomados de outros.

MUTUUS, a, um, adj. - Mútuo, recíproco. Drupis mutua pressione angulatis (FB): com as drupas angulosas em virtude da pressão que umas exercem sobre outras.

MYSTERIUM, i, subs. n. 2 - Segredo; mistério. Cf. physiologus.

\section{SUMMARY}

Botanical Latin-Portuguese Classical Lexicon - This is the fourth contribution of this work, embracing the letter between $I$ and $M$. The explanation given in the first one (see Bibliography) serves to the present also.

\section{BIBLIOGRAFIA}

A bibliografia já foi transcrita no seguinte trabalho:

Rizzini, C.T. e C.M.R. RibEIRO. 1979. Dicionário Botânico Clássico Latino-português Averbado. I-A e B. Arquivos do Jardim Botânico 23: 49-89. 